\title{
Roles of TRAFs in Ischemia-Reperfusion Injury
}

\author{
Wei Zhou', Danni Lin ${ }^{1,2}$, Zibiao Zhong1 and Qifa Ye ${ }^{1,3 *}$ \\ ${ }^{1}$ Zhongnan Hospital of Wuhan University, Institute of Hepatobiliary Diseases of Wuhan University, Transplant Center of \\ Wuhan University, Hubei Key Laboratory of Medical Technology on Transplantation, Engineering Research Center of Natural \\ Polymer-based Medical Materials in Hubei Province, Wuhan, China, ${ }^{2}$ The First Affiliated Hospital, Zhejiang University School \\ of Medicine, Department of Hepatobiliary and Pancreatic Surgery, Zhejiang Provincial Key Laboratory of Pancreatic Disease, \\ Innovation Center for the Study of Pancreatic Diseases, Hangzhou, China, ${ }^{3}$ The Third Xiangya Hospital of Central South \\ University, Research Center of National Health Ministry on Transplantation Medicine Engineering and Technology, Changsha, \\ China
}

\section{OPEN ACCESS}

Edited by:

Qi Cao,

University of Maryland, Baltimore,

United States

Reviewed by:

Jiangang Shen,

The University of Hong Kong,

Hong Kong

Pasquale Vito,

University of Sannio, Italy

Zhong Wang,

Soochow University, China

${ }^{*}$ Correspondence:

Qifa Ye

yqf_china@163.com

Specialty section:

This article was submitted to Signaling,

a section of the journal

Frontiers in Cell and Developmental

Biology

Received: 23 July 2020

Accepted: 05 October 2020

Published: 05 November 2020

Citation:

Zhou W, Lin D, Zhong Z and Ye Q (2020) Roles of TRAFs

in Ischemia-Reperfusion Injury. Front. Cell Dev. Biol. 8:586487. doi: 10.3389/fcell.2020.586487
Tumor necrosis factor receptor-associated factor (TRAF) proteins are a family of signaling molecules that function downstream of multiple receptor signaling pathways, and they play a pivotal role in the regulation of intracellular biological progresses. These TRAFdependent signaling pathways and physiological functions have been involved in the occurrence and progression of ischemia-reperfusion injury (IRI), which is a common pathophysiological process that occurs in a wide variety of clinical events, including ischemic shock, organ transplantation, and thrombolytic therapy, resulting in a poor prognosis and high mortality. IRI occurs in multiple organs, including liver, kidney, heart, lung, brain, intestine, and retina. In recent years, mounting compelling evidence has confirmed that the genetic alterations of TRAFs can cause subversive phenotype changes during $|R|$ of those organs. In this review, based on current knowledge, we summarized and analyzed the regulatory effect of TRAFs on the IRI of various organs, providing clear direction and a firm theoretical basis for the development of treatment strategies to manipulate TRAF proteins or TRAF-dependent signaling pathways in IRI-related diseases.

Keywords: TRAFs, ischemia-reperfusion injury, hypoxia/reoxygenation, inflammation, ubiquitination

\section{BACKGROUND}

Tumor necrosis factor receptor-associated factors (TRAFs) were identified as the signaling adaptors that positively and negatively regulate the signal transduction pathways of various receptors, including the TNF-R superfamily, Toll-like receptors (TLRs), NOD-like receptors (NLRs), RIG-I-like receptors (RLRs), and cytokine receptors (Fang et al., 2017; Dhillon et al., 2019;

Abbreviations: ALDOA, aldolase A; aPKC, atypical protein kinase C; ASK1, apoptosis signal-regulating kinase 1; AS-IV, Astragaloside IV; BBB, blood brain barrier; BMAL1, aryl hydrocarbon receptor nuclear translocator-like protein 1; CK, creatine kinase; CSFV, classical swine fever virus; EAD, early allograft dysfunction; ER, endoplasmic reticulum; EV71, enterovirus 71; HBV, hepatitis B virus; HCC, hepatocellular carcinoma; hMSCs, human mesenchymal stem cells; HPV, human papilloma viruses; H/R, hypoxia/reoxygenation; IBD, inflammatory bowel disease; IFN-I, type I interferon; IPC, ischemic preconditioning; IPostC, ischemic postconditioning; IRI, ischemia-reperfusion injury; lncRNA, long non-coding RNA; LPS, lipopolysaccharide; LRIP, limb remote ischemic postconditioning; LV, left ventricular; MAPK, mitogen-activated protein kinase; Mbd2, methyl-CpG binding domain protein 2; miRNAs, microRNA; MLKL, mixed-lineage kinase domain-like; NAS,

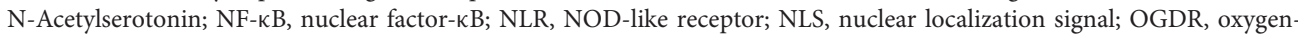
glucose deprivation reperfusion; ORF3a, open reading frame 3a; PI3K, phosphatidylinositol-3-kinase; PreD-SCP, preactivated and disaggregated shape-changed platelet; RLR, RIG-I-like receptor; SAB, salvianolic acid B; SARS-CoV, severe acute respiratory syndrome coronavirus; SLE, systemic lupus erythematosus; Sphk1, sphingosine kinase 1; TAK1, transforming growth factor- $\beta$-activated kinase 1 ; TGF- $\beta$, transforming growth factor- $\beta$; TLR, Toll-like receptor; TRAF, Tumor necrosis factor receptor-associated factor; TUDCA, tauroursodeoxycholic acid. 
Swaidani et al., 2019). There are six typical members (TRAF1-6) and an atypical member (TRAF7) in mammalian cells (Park, 2018; He et al., 2020). Most TRAFs share a similar C-terminal TRAF domain, a distinct feature of the typical TRAF proteins except for TRAF7 (in which seven WD40 repeats replace the TRAF domain), which contain an N-terminal coiled-coil domain (TRAF-N) and a highly conserved C-terminal $\beta$-sandwich domain (TRAF-C or MATH domain) (Arkee and Bishop, 2019; Stevers et al., 2019). Furthermore, all TRAF members, with the exception of TRAF1, contain a similar N-terminal RING domain, followed by one or more zinc fingers (Zapata et al., 2018; Arkee and Bishop, 2019; Stevers et al., 2019; Figure 1). The TRAF domain is responsible for mediating the oligomerization between the TRAF proteins, as well as their association with upstream regulators and downstream effectors. The RING domain is found in many E3 ubiquitin ligases and is responsible for mediating proteins' ubiquitination ( $\mathrm{Lu}$ et al., 2018; Zapata et al., 2018; Arkee and Bishop, 2019; Stevers et al., 2019). Due to their structural characteristics, TRAF proteins are involved in a variety of intracellular pathophysiological processes, including cell apoptosis, proliferation, differentiation, autophagy, necroptosis, pyroptosis, immune, and inflammatory responses (Lan et al., 2017; Robeson et al., 2018; Dhillon et al., 2019; Li et al., 2019b; Swaidani et al., 2019; Zhang X. et al., 2019). Specially, since TRAFs were discovered in TNF-R signaling, its role has been expanded to include involvement in more and more other inflammatory cytokine receptors, such as receptors for IL-2, IL-6, IL-1 $\beta$, IL-17, IL-18, IL-33, type I IFNs, type III IFNs, M-CSF, GM-CSF, and C-type lectin receptors (Dhillon et al., 2019; Swaidani et al., 2019). Certainly, as intracellular scaffolding molecules, TRAFs play an indispensable role via the complex interactions with the inflammatory cytokine receptors in regulating pathophysiological processes in many human diseases, including autoimmune diseases, cancers, atherosclerosis, and type II diabetes, and they even have been recommended as suitable targets for therapeutic intervention (Choi et al., 2018; Nagashima et al., 2018; Zhu et al., 2018; Dhillon et al., 2019; Sajjad et al., 2019; Sangare et al., 2019). Meanwhile, the biological and functional roles of TRAFs in ischemia-reperfusion injury (IRI) of various organs have received much attention in recent years.

IRI can occur in a variety of tissues and organs, including the liver, kidney, heart, lung, brain, intestine, and retina, leading to severe pathophysiological damage to the primary organ or even remote organs, partly due to explosive oxidative stress, inflammation and destruction of the physiological body barrier. The occurrence of IRI leads to a poor prognosis in many diseases, such as neuronal damage caused by ischemic shock, acute cardiopulmonary damage caused by thrombolytic therapy, and visual impairment caused by retinopathy (Chen et al., 2017; Li et al., 2019d; Hui et al., 2020; Kohler et al., 2020). However, there is still no exact treatment method in clinical guidelines due to the devastating pathological damage and complex molecular mechanisms involved in IRI. To achieve better therapeutic effects, increasing attention has been paid to the study of IRI in recent years. Previous studies have shown that the main mechanisms of IRI include apoptosis and necrosis (Zhou H. et al., 2017; Li et al., 2018a; Xu T. et al., 2019), autophagy (Russo et al., 2018;
Yu et al., 2018), and activation of the complement and lymphatic systems (Gigliotti et al., 2013; Bajwa et al., 2016). The signaling pathways involved mainly include the nuclear factor- $\kappa \mathrm{B}(\mathrm{NF}-\kappa \mathrm{B})$ (Li et al., 2018a; Zhang R. et al., 2018), apoptosis signal-regulating kinase 1 (ASK1) (Qin et al., 2018), transforming growth factor$\beta$-activated kinase 1 (TAK1), and autophagy (ATG) pathways (Li et al., 2018d; Chen et al., 2020). Recently, IRI events have increasingly been shown to involve newly proposed mechanisms such as necroptosis (Linkermann et al., 2012; Li et al., 2018c; Zhou et al., 2018), pyroptosis (Qiu et al., 2017; Tajima et al., 2019), and ferroptosis (Gao et al., 2015; Tonnus and Linkermann, 2016; Li et al., 2019f), which have attracted substantial attention and keen interest.

Convincing evidence in recent years has proven that most TRAF proteins, except TRAF4 and TRAF7, are involved in the development of IRI by regulating respective molecular mechanisms to play a similar or opposite effect on various organs (Figure 2). In this review, we will state and elucidate the specific role of most TRAF molecules in the IRI of different organs to provide a theoretical basis for formulating treatment strategies for diseases related to IRI, and provide directions for further TRAFs exploration.

\section{Basic Concept and Network Regulate of TRAFs in Cellular Signaling Cascades TRAF1}

TRAF1, a unique member of the TRAF family, lacks the $\mathrm{N}$-terminal RING domain, whose expression is low in resting cells and is only found in activated dendrites, lymphocytes, and certain epithelia (Kim C. M. et al., 2017; Ivagnès et al., 2018). In addition, TRAF1 exerts its primary function in specific organs in mice and humans, including the spleen, lung, and testis (Wang et al., 2018). Although the structure of TRAF1 is more simple than other TRAFs and its expression is restricted, it still plays an indispensable role in regulating certain intracellular biological progresses, including cellular innate immunity and apoptosis signaling. For apoptosis, TRAF1 seems to exert conflicting biologic effects depending on the specific cell type. In immune cells, TRAF1 shows an anti-apoptotic function in TNFR2 signaling via direct interaction with TNFR2; however, it plays a pro-apoptotic function in neuronal cell death (Lu et al., 2013; Kim C. M. et al., 2017). Interestingly, TRAF1-deficient mice showed hyper-inflammation in obese visceral adipose tissue, failure to gain weight, and improved insulin resistance (Anto Michel et al., 2018). Furthermore, a study of septic, TRAF1-deficient mice showed increased susceptibility to lipopolysaccharide (LPS)induced septic shock (Abdul-Sater et al., 2017). Clearly, based on its physiological function, TRAF1 plays an important role in many human inflammation and metabolic diseases.

\section{TRAF2}

TRAF2 is the most extensively studied member of the TRAF family in terms of structure and function. Similar to other TRAF proteins, TRAF2 contains the conventional N-terminal RING domain, zinc finger domain, and C-terminal TRAF domain (Bhat et al., 2018; Chen et al., 2018). Recently, a study showed that the zinc finger domain of TRAF2, instead of the 


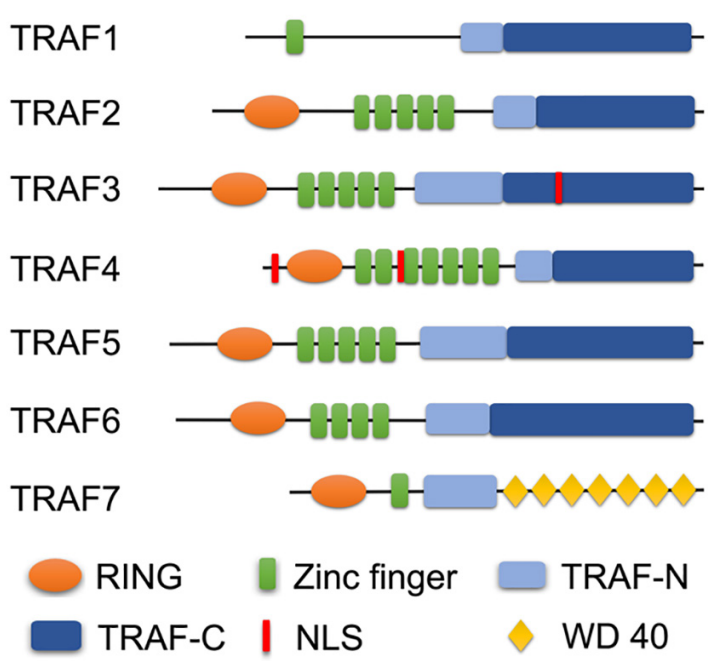

FIGURE 1 | Domain organization of TRAF family. A schematic diagram represents the basic structural features of TRAF1-7. All TRAF members, except TRAF1, contain a similar N-terminal RING domain, followed by one or more zinc fingers. Most TRAFs share a similar TRAF domain divided into an $\mathrm{N}$-terminal coiled-coil domain (TRAF-N) and a C-terminal $\beta$-sandwich domain (TRAF-C or MATH domain), except TRAF7 (in which seven WD40 repeats replace the TRAF domain). Especially, TRAF3 and TRAF4 contain the nuclear localization signal (NLS) sequence. conventional substrate recognition C-terminal TRAF domain, was responsible for interacting with the aryl hydrocarbon receptor nuclear translocator-like protein 1 (BMAL1) (Chen et al., 2018). Therefore, the functions of substrate recognition domains in TRAF2 differ according to the substrates.

Organizationally, TRAF2 is widely expressed in various tissues, including the brain, heart, liver, spleen, lung, kidney, testis, and skeletal muscle, and has the highest expression in the spleen in mice (Qu et al., 2017). In terms of regulation, as an E3 ubiquitin ligase, TRAF2 is regulated by complex managers, including cIAP-1, siah2 and A20 for ubiquitination and degradation (Zhang et al., 2020), and CYLD, USP4, USP25 and USP48 for the deubiquitination (Li et al., 2002, 2018b; Trompouki et al., 2003). Surprisingly, USP48 knockdown increased the abundance of lysine 48 (K48)-linked ubiquitination but not the K63-linked ubiquitination of TRAF2, and subsequently reduced its stability (Li et al., 2018b). These complex managers contribute to TRAF2's regulation of multiple cellular responses, such as anoikis, cell proliferation, apoptosis and necroptosis, and immune and inflammatory responses (Guo et al., 2017; da Silva et al., 2019), contributing to the pathogenesis of many diseases, especially cancers, including hepatocellular carcinoma (HCC) and gastrointestinal cancers (Hirsova et al., 2017; Schneider et al., 2017; Xu et al., 2017), prostate and pancreatic cancers (Wei et al., 2017; Chen et al., 2018), lung cancer (Lu et al., 2018), and ovarian and breast cancer (da Silva et al., 2019; Zhang et al., 2020).

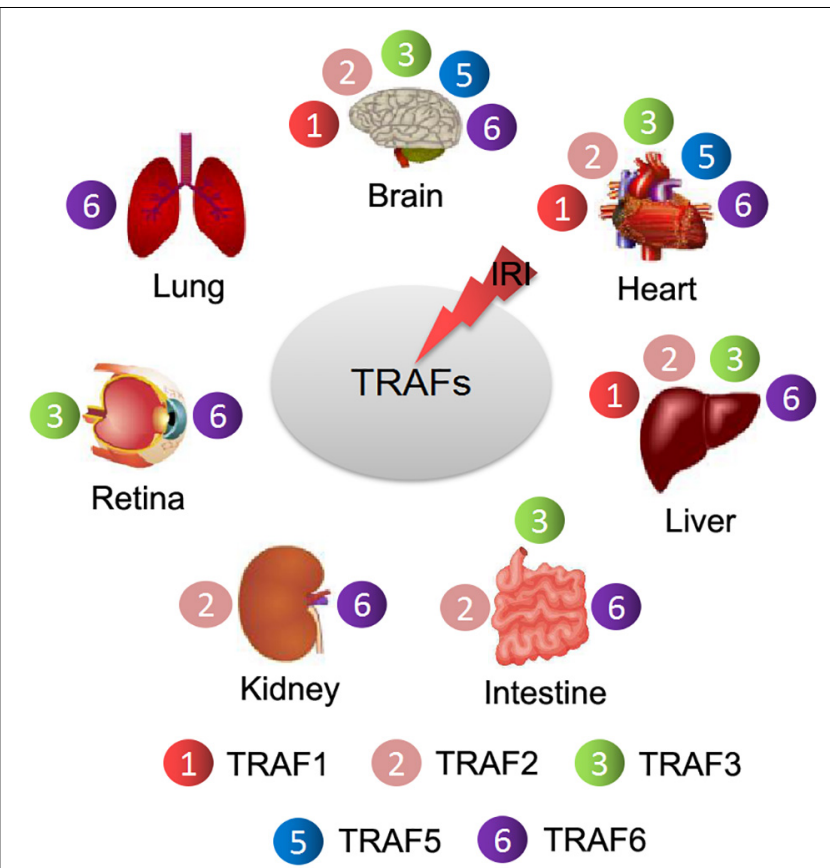

FIGURE 2 | Different TRAF members are involved in the regulation of IRI in different organs. TRAF1/2/3/5/6 regulate cerebral and myocardial IRI. TRAF1/2/3/6 are involved in liver IRI. TRAF2/3/6 participate in the regulation of intestinal IRI. TRAF2/6 are related to renal IRI. TRAF3/6 are involved in retinal $|R|$. TRAF6 is correlated with lung IRI.

\section{TRAF3}

Anatomically, similar to most TRAF members, TRAF3 contains a conserved TRAF domain, zinc finger domain, and a RING domain (Xie et al., 2020). Interestingly, recent studies have found that the TRAF-C domain of TRAF3 contains the nuclear localization signal (NLS) sequence (Mambetsariev et al., 2016), suggesting that TRAF3 may have a biological function in the nucleus besides its canonical functions in the cell membrane and cytoplasm. However, probably due to the postnatal lethality of global TRAF3 deficiency, the functions of TRAF3 are more elusive than other members (Hu et al., 2016; Wallis and Bishop, 2018). TRAF3 functions were delayed until the mature application of gene conditional knockout (Wallis and Bishop, 2018), and primarily included a role in immune and inflammatory responses via regulating the NF- $\kappa$, mitogenactivated protein kinase (MAPK) and type I interferon (IFNI) pathways (Perez-Chacon et al., 2018; Fochi et al., 2019). Importantly, TRAF3 plays a master role in regulating the homeostasis and function of B cells, where it is involved in their proliferation, survival, and differentiation (Perez-Chacon et al., 2018; Whillock et al., 2019). Recently, TRAF3 is getting increasing attention in various viral infections, including severe acute respiratory syndrome coronavirus (SARS-CoV) (Siu et al., 2019), hepatitis B virus (HBV) (Xie et al., 2020), human papilloma viruses (HPV) (Zhang J. et al., 2018; Xiao et al., 2019), and enterovirus 71 (EV71) (Gu et al., 2017), by regulating the IFN-I or NF- $\kappa$ B pathways. In SARS-CoV research, TRAF3, but not TRAF2 
or TRAF6, was required for SARS-CoV open reading frame $3 \mathrm{a}$ (ORF3a)-induced activation of NF- $\kappa B$ (Siu et al., 2019). However, the effects of TRAF3 on NF- $\kappa$ B pathways are controversial. A prevalent view holds that TRAF3 negatively regulates the noncanonical NF-кB pathway (Li et al., 2019a,c; Zhang Z. et al., 2019), but many certified events have shown that TRAF3 can activate both canonical and non-canonical NF- $\kappa$ B pathways (He et al., 2004; Bista et al., 2010). NF- $\mathrm{B}$ pathways are vital regulators of many pathological events, including inflammation and apoptosis, in ischemic injury (Gong et al., 2015; Xu et al., 2018). Thus, as a crucial regulator of NF- $\kappa \mathrm{B}$ pathways, TRAF3 has attracted much attention in the study of IRI of various organs.

\section{TRAF4}

TRAF4 is a unique member of the TRAF family, in terms of both structure and function. Firstly, TRAF4 is an ancestral member, due to the fact that other TRAFs members (except TRAF6) have evolved to a certain extent (Cai et al., 2017). Secondly, TRAF4 is the only member that has three cysteinerich motifs associated with TRAF and RING domains, followed by seven zinc fingers (Rousseau et al., 2014; Yang et al., 2015). In addition, TRAF4 has the canonical NLS sequence, similar to TRAF3 (Mambetsariev et al., 2016; Das et al., 2019). Moreover, although it has been confirmed that TRAF4 is widely expressed in adult tissues, its subcellular localization has been controversial for years (Shen et al., 2013; Yi et al., 2013). The mainstream views hold that it is broadly located in the cell membrane, cytoplasm, and nucleus (Rousseau et al., 2014; Ren et al., 2015). Perhaps due to the particularity of its structure and expression, TRAF4 plays an important role in developmental steps, such as tracheal ring formation, neural tube closure, and axial skeleton formation (Kim E. et al., 2017). However, there were no obvious immunological defects or lymphocyte changes in TRAF4-deficient mice (Kang et al., 2018), suggesting that TRAF4 may not have a significant impact on immune function in mice. Moreover, although researchers have confirmed that TRAF4 did not bind to TNF receptors, or only weakly interacted with a few TNF receptor family members under certain conditions (Ren et al., 2015), TRAF4 is a crucial regulator in the transforming growth factor- $\beta$ (TGF- $\beta$ ), Wnt- $\beta$-catenin, and phosphatidylinositol-3-kinase (PI3K)/AKT pathways, which are involved in tumorigenesis and progression (Kang et al., 2018). However, unlike TRAF1/2/3/5/6, study about TRAF4's involvement in IRI is few.

\section{TRAF5}

TRAF5 is much less studied than TRAF3, although TRAF5 shares the highest sequence with TRAF3 in the TRAF family (Foight and Keating, 2016; Kim et al., 2020). Similarly, TRAF5 contains an $\mathrm{N}$-terminal RING domain, five zinc fingers at the middle of its sequence, a coiled-coil domain, and a MATH domain included in the C-terminal TRAF domain (Xu et al., 2020). TRAF5 mainly exists in immune organs, including the spleen and thymus, and is also abundantly expressed in the epidermis, lungs and kidneys (Nagashima et al., 2018; Xia et al., 2019). Based on its characteristics of expression, TRAF5 is closely related to many immune-related diseases, such as systemic lupus erythematosus
(SLE), inflammatory bowel disease (IBD), and the infection of classical swine fever virus (CSFV) (Wang et al., 2015; Shang et al., 2016; Lv H. et al., 2018). In addition, TRAF5 plays a vital role in the progression of various cancers, including HCC, colorectal cancer, breast cancer, and prostate cancer, via regulating cell proliferation, apoptosis, and survival (Ling et al., 2018; Jiang et al., 2020). Interestingly, there have been studies showing that TRAF5 is associated with chronic inflammation-related diseases, which demonstrate that TRAF5 plays protective roles in atherosclerosis and obesity-induced non-alcoholic fatty liver disease or nonalcoholic steatohepatitis (Missiou et al., 2010; Gao et al., 2016).

\section{TRAF6}

TRAF6, one of the most evolutionarily ancient members of TRAF family, is ubiquitously expressed in various tissues and cell types (Cai et al., 2017; Jiang et al., 2017; Lalani et al., 2018). It contains a characteristic C-terminal TRAF domain, a similar N-terminal RING domain, followed by at least four zinc fingers ( $\mathrm{Hu}$ et al., 2017; Fu et al., 2018). Similar to TRAF2/3/5, the RING domain of TRAF6 possesses non-conventional E3 ubiquitin ligase activity. Generally, K48-linked ubiquitination of TRAF6 is responsible for the degradation of substrate, whereas K63-linked ubiquitination is responsible for signaling activation and protein trafficking (Hu et al., 2017; Lv Y. et al., 2018). However, K63-linked ubiquitination can also promote the degradation of lysosomalmediated substrate proteins ( $\mathrm{Lu}$ et al., 2017). Interestingly, TRAF6 can be auto-ubiquitinated through K63-linked ubiquitin chains, which is a vital prerequisite for its activation (Min et al., 2018). In addition to being an E3 ubiquitin ligase, TRAF6 is also an adapter protein, which bridges between the TLRs, TNF-R superfamily, and IL-1 receptors with downstream signal pathways, especially MAPK and NF- $\kappa$ B pathways, regulating immune and inflammatory responses (David et al., 2018; Fu et al., 2018). Unquestionably, these receptors and pathways are fatal for cell inflammation, survival, and death (Zhou et al., 2015), which commonly occurs in the pathophysiological processes of IRI.

\section{TRAF7}

TRAF7, the latest identified member, is the other unique protein of the TRAF family besides TRAF4. TRAF7 is also the only atypical member in TRAF family, as it contains seven WD40 repeat domains instead of the common TRAF domain (Clark et al., 2013). Similar to the TRAF domain, the WD40 repeat domains are responsible for the protein-protein and proteinDNA interactions (Zotti et al., 2017). In addition, TRAF7 also possesses the N-terminal RING domain and the adjacent zinc finger, similar to most other TRAF members (Tokita et al., 2018). Thus far, the biological function of TRAF7 remains elusive and is under investigation. Most studies at present are about the correlativity between mutations in TRAF7 and various tumors, including meningiomas, adenomatoid tumors and intraneural perineuriomas (Reuss et al., 2013; Klein et al., 2017; Goode et al., 2018), and all such mutations are heterozygous missense mutations, which cluster within the mutational hotspots in the WD40 domains (Klein et al., 2017; Goode et al., 2018). The latest research showed that, as a E3 ubiquitin ligase like most other TRAF members, TRAF7 played an important role in the 
regulation of inflammatory response, cell apoptosis, and tumor progression by the lysosomal degradation of NF- $\mathrm{B}$ essential modulator and the proteasomal degradation of Krüppel-like factor 4, respectively (He et al., 2020). In addition, a study showed that TRAF7 played a major role in the suppression of endothelial hyperpermeability induced by inflammatory stimuli and roundabout4, an endothelial cell-specific receptor, which could enhance the function of TRAF7 (Shirakura et al., 2019). It can be seen that TRAF7 can cooperate with other molecules to regulate inflammation and cell apoptosis. It may also play a role in IRI, but according to our knowledge, there is no relevant research in this regard now.

\section{Roles of TRAFs and Agents for Regulating TRAFs in IRI of Different Organs TRAF1}

According to current research, TRAF1 plays a vital role in cerebral, liver, and myocardial IRI (Lu et al., 2013; Zhang et al., 2014; Huang X. et al., 2019; Xu W. et al., 2019). Cerebral IRI is the main culprit causing ischemic stroke, accounting for $\sim 80 \%$ of total stroke cases, which has caused adult neurological disability globally and presented a very high mortality rate yearly (Li et al., 2019d,e). Current treatment strategies are limited for ischemic stroke because the mechanisms of cerebral IRI are extremely complicated. Surprisingly, TRAF1 transgenic (TG-TRAF1) mice showed enlarged stroke lesions while TRAF1-deficient (TRAF1KO) mice showed significant lesion reduction ( $\mathrm{Lu}$ et al., 2013). Meanwhile, an in vitro experiment also showed that increased TRAF1 expression resulting from the infection of adenovirusharboring human TRAF1 cDNA (Ad-TRAF1) presented more neuronal apoptosis than decreased TRAF1 expression caused by treatment with TRAF1 short hairpin RNA (Ad-shTRAF1) (Lu et al., 2013). Mechanistically, TRAF1 promoted ischemic cerebral injury by directly interacting with ASK1 (Lu et al., 2013). Furthermore, it may be the $\mathrm{N}$-terminal region or kinase domain of ASK1, rather than the C-terminal region, that is capable of interacting with TRAF1, and that the TRAF domain is essential for TRAF1-induced neuronal injury after ischemia. Moreover, Fas-/FasL-regulated necroptosis was also involved in the process of TRAF1 cerebral IRI regulation (Lu et al., 2013). Unfortunately, there was no in-depth exploration of the relationship between TRAF1 and necroptosis in the study.

Subsequently, it has also been verified that the TRAF1/ASK1 axis promotes liver IRI and myocardial IRI (Zhang et al., 2014; Huang X. et al., 2019; Xu W. et al., 2019). Liver IRI is a common pathological process that occurs in hemorrhagic shock, trauma, liver resection, and liver transplantation, which lead to early allograft dysfunction (EAD), an important cause of morbidity and mortality in liver transplant recipients (Monga, 2018; Ni et al., 2019; Nakamura et al., 2020). TRAF1 deficiency inhibited inflammation and cell death, and TRAF1-KO mice were resistant to liver IRI (Zhang et al., 2014). In vitro, the overexpression of miR-214 reduced hepatocyte apoptosis following hypoxia/reoxygenation (H/R) injury by negatively regulating the TRAF1/ASK1/JNK pathway (Huang $\mathrm{X}$. et al.,
2019). In myocardial IRI, TRAF1-KO mice showed decreased cardiomyocyte apoptosis and milder inflammatory response than the TRAF1 wild-type (WT) mice. Explicitly, TRAF1 aggravated primary neonatal cardiomyocyte inflammation and apoptosis via promoting the ASK1/JNK/p38 cascades in response to $H / R$ (Xu W. et al., 2019). However, TRAF1 is also expressed in fibroblasts and endothelial cells of the heart. Whether TRAF1 contributes to the regulation of non-cardiomyocytes in IRI is still unclear. Overall, current research showed that TRAF1 played an important role in cerebral, liver, and myocardial IRI, and the TRAF1/ASK1 axis was the common signaling pathway involved in IRI regulation for these organs.

\section{TRAF2}

Similarly, TRAF2 plays a vital role in regulating IRI of various organs, including myocardial, intestine, brain, kidney, and liver, through different molecular mechanisms (Xia et al., 2012; Tzeng et al., 2014; Tan et al., 2015; Zhou W. et al., 2017; Li et al., 2019b). Myocardial infarction remains one of the leading health problems around the world. However, recanalization of previously blocked blood vessels can cause serious myocardial IRI, which is a leading risk factor for heart failure (Zhu et al., 2019; Kohler et al., 2020). An early myocardial reperfusion period can cause endoplasmic reticulum (ER) stress and subsequently increase the expression of ER stress markers, including TRAF2 (Wang Z. H. et al., 2014). Later, a study showed that cardiac-restricted expression of dominant negative TRAF2 (MHC-TRAF2 ${ }_{D N}$ ) mice had significantly worse left ventricular (LV) functional recovery, increased Evans blue dye uptake, and increased creatine kinase (CK) release (Tzeng et al., 2014). Conversely, low levels of TRAF2 expression in the mice hearts (MHC-TRAF2 ${ }_{L C}$ ) significantly improved LV functional recovery (Burchfield et al., 2010; Tzeng et al., 2014). Clearly, TRAF2 played a cardioprotective role in myocardial IRI.

We have also proven the protective effects of TRAF2 in intestinal IRI, which occurs in a wide variety of clinical conditions, including hemorrhagic shock, acute mesenteric ischemia, and organ transplantation, resulting in a high mortality rate that range from 70 to $80 \%$ (Higuchi et al., 2008; Jia et al., 2020). In our research, we verified that PKC $\zeta$, a member of the atypical protein kinase $\mathrm{C}$ (aPKC) subfamily, phosphorylated TRAF2 at Ser ${ }^{55}$, rather than at Ser ${ }^{11}$, activating NF- $\kappa$ B but inhibiting c-Jun to attenuate cell apoptosis, leading to protection against the injury induced by intestinal ischemia-reperfusion (Zhou W. et al., 2017). In terms of cerebral IRI, the role of TRAF2 seems to be controversial in current research. One study showed that in an in vitro model simulating cerebral IRI, the knockdown of TRAF2 in microglia reduced neuronal injury induced by oxygen-glucose deprivation reperfusion (OGDR), and the sphingosine kinase 1 (Sphk1)/TRAF2/NF- $\kappa \mathrm{B}$ pathway was responsible for the increased neuronal apoptosis following OGDR (Su et al., 2017). However, a recent study suggested that TRAF2 interacted with mixed-lineage kinase domain-like (MLKL) protein, protecting against cerebral IRI by suppressing necroptosis (Li et al., 2019b). Thus, it can be seen that TRAF2 may play different roles by interacting with different regulatory proteins in specific cell types. In renal and liver IRI, TRAF2 is 
only involved as a participant in these pathological processes (Ben Mkaddem et al., 2010; Kim and Lee, 2012; Xia et al., 2012; Tan et al., 2015). However, there has been no in-depth discussion of its specific mechanism. It follows that TRAF2 plays complicated role in IRI of various organs, and further research needs to be conducted.

\section{TRAF3}

TRAF3 is ubiquitously expressed in multiple organs, primarily including the brain, liver, heart, lung, and spleen (Liu F. et al., 2018; Dai et al., 2019). The TRAF3-related IRI was mainly concentrated in the brain, liver, heart, intestine and retina (Gong et al., 2015; Hu et al., 2016; Liu X. et al., 2018; Dai et al., 2019; Ge et al., 2020). In cerebral IRI, TRAF3 is a central regulator through its interaction with and phosphorylation of TAK1 (Gong et al., 2015). The TRAF3-TAK1 signaling pathway promoted neural cell death, inflammatory response, and oxidative stress in cerebral IRI by regulating the JNK, NF- $\kappa B$, and Rac-1/NADPH oxidase pathways, respectively (Gong et al., 2015). The underlying mechanism by which TRAF3 regulates canonical NF- $\kappa \mathrm{B}$ pathways remains largely unclear in previous studies. Surprisingly, the cerebral IRI research suggested that TRAF3 promoted the activation of canonical NF- $\kappa$ B pathways via phosphorylation of TAK1 (Gong et al., 2015), which provided new evidence for TRAF3's role in regulating the canonical NF$\kappa \mathrm{B}$ pathway. Similarly, TRAF3 promoted the liver damage and inflammation induced by liver IRI by directly binding to TAK1, which activated the downstream JNK and NF- $\kappa \mathrm{B}$ pathways ( $\mathrm{Hu}$ et al., 2016). The effects of TRAF3 on JNK pathways were focused on myocardial IRI, which showed that TRAF3 promoted apoptosis, inflammation, and oxidative stress in the hearts of mice with IRI by JNK activation (Liu X. et al., 2018). Although TRAF3 initially exerted a negative regulatory effect on the JNK pathway (Matsuzawa et al., 2008), these IRI studies have shown that TRAF3 can activate JNK under certain conditions.

Additionally, the effects of TRAF3 on NF- $\kappa$ B pathways were verified in intestinal IRI. TRAF3's regulation of NF- $\kappa$ B is time-dependent in intestinal IRI. Research showed that TRAF3 promoted the expression of NF- $\mathrm{BB}$ at $90 \mathrm{~min}$ of reperfusion in vivo; however, it inhibited the expression of $\mathrm{NF}-\kappa \mathrm{B}$ with further prolongation, and the results were verified in vitro (Dai et al., 2019). Moreover, research identified TRAF3 as a target gene of miR-29b-3p, which plays a protective role in intestinal IRI by inhibiting the TRAF3 signal pathway (Dai et al., 2019). The regulation of TRAF3 by non-coding RNA, mainly microRNAs (miRNAs), and long non-coding RNAs (lncRNAs), has also received attention in recent research of retinal IRI, which is common in diabetic retinopathy, glaucoma, and retinal vascular occlusive disorders, in which it leads to irreversible visual impairment and eventually results in blindness (Ge et al., 2020). In one study, methyl-CpG binding domain protein $2(\mathrm{Mbd} 2)$, one of the DNA methylation readers, aggravated retinal cell apoptosis by targeting the Mbd2-associated long non-coding RNA 1 (Mbd2-AL1)/miR-188-3p/TRAF3 axis (Ge et al., 2020). However, the downstream pathways of TRAF3 were unexplored in retinal IRI. Therefore, based on the above research, it can be concluded that TRAF3 promotes injury induced by ischemia-reperfusion.

\section{TRAF5}

In addition to chronic inflammatory diseases, TRAF5 also plays important roles under various stresses, such as cerebral and myocardial IRI (Wang L. et al., 2013; Xu et al., 2020). However, based on the current research, TRAF5 seems to play a contradictory role in cerebral and myocardial IRI (Figure 3). In cerebral IRI, neuron-specific TG-TRAF5 mice exhibited aggravated blood brain barrier (BBB) disruption, more neuronal apoptosis, and increased inflammatory response compared with TRAF5-KO mice (Wang L. et al., 2013). Furthermore, cerebral IRI research proved that the deletion of TRAF5 inhibited NF$\kappa \mathrm{B}$ activity, but enhanced the Akt/FoxO1 pathway, in which FoxO1 is phosphorylated by p-Akt, leading to nuclear export and inhibiting transcription factor activity (Wang L. et al., 2013; Figure 3). Conversely, in myocardial IRI, TRAF5 deficiency both in vivo and in vitro exacerbated cardiomyocyte inflammation and apoptosis by activating the NF- $\kappa$ B pathway while inhibiting the Akt/FoxO1 pathway (Xu et al., 2020; Figure 3). The inconsistent effects of TRAF5 in cerebral and myocardial IRI are possibly due to the organ-specific function of TRAF5. Moreover, the expression of TRAF5 is low in various cell types of the heart, including fibroblasts, cardiomyocytes, and endothelial cells. Cardiomyocytes, along with other non-cardiomyocytes, possibly contribute to the synergistic effects of TRAF5 in myocardial IRI (Xu et al., 2020).

Additionally, the effects of TRAF5 on the NF- $\kappa$ B pathway are controversial. In agreement with the view about its role in myocardial IRI, TRAF5 deficiency aggravated cardiac dysfunction partly by activating NF- $\mathrm{B}$-dependent inflammatory responses under pressure overload, and the same view was verified in the research of inflamed colons (Bian et al., 2014; Shang et al., 2016). Meanwhile, there are studies suggesting that TRAF5 promoted the activation of the NF- $\kappa$ B pathway (Shang et al., 2016), which is more in line with the view of its role in cerebral IRI. Therefore, the effects of TRAF5 on IRI and the NF$\kappa \mathrm{B}$ pathway might be tissue- or disease-specific and need to be studied more thoroughly in the future.

\section{TRAF6}

As an intermediate mediator between receptors and pathways, TRAF6 is highly involved in IRI of various organs. For example, according to our knowledge, the TLR4/MyD88/TRAF6/NF- $\mathrm{B}$ axis contributes to the injuries induced by ischemia-reperfusion of multiple organs, including the myocardia, liver, kidney, and retina (Li et al., 2010; Qi et al., 2014; Wang X. et al., 2014; Shao et al., 2016). Meaningfully, many drugs or compounds can reduce cerebral IRI targeting the axis, including Astragaloside IV (AS-IV), bicyclol, salvianolic acid B (SAB), and dioscin (Zhang et al., 2013; Tao et al., 2015; Wang et al., 2016; Li M. et al., 2017; Figure 4). Moreover, aloin and N-Acetylserotonin (NAS) were respectively involved in the regulating of liver and intestinal IRI by targeting TRAF6 (Du et al., 2019; Sukhotnik et al., 2019; Figure 4), which provides targets for clinical treatment of liver and intestinal IRI-related diseases. In addition, miRNA-based treatments for IRI are very popular in recent years (Huang Z. et al., 2019; Liang et al., 2019). Many studies have shown that the increased expression of miR-146a could 


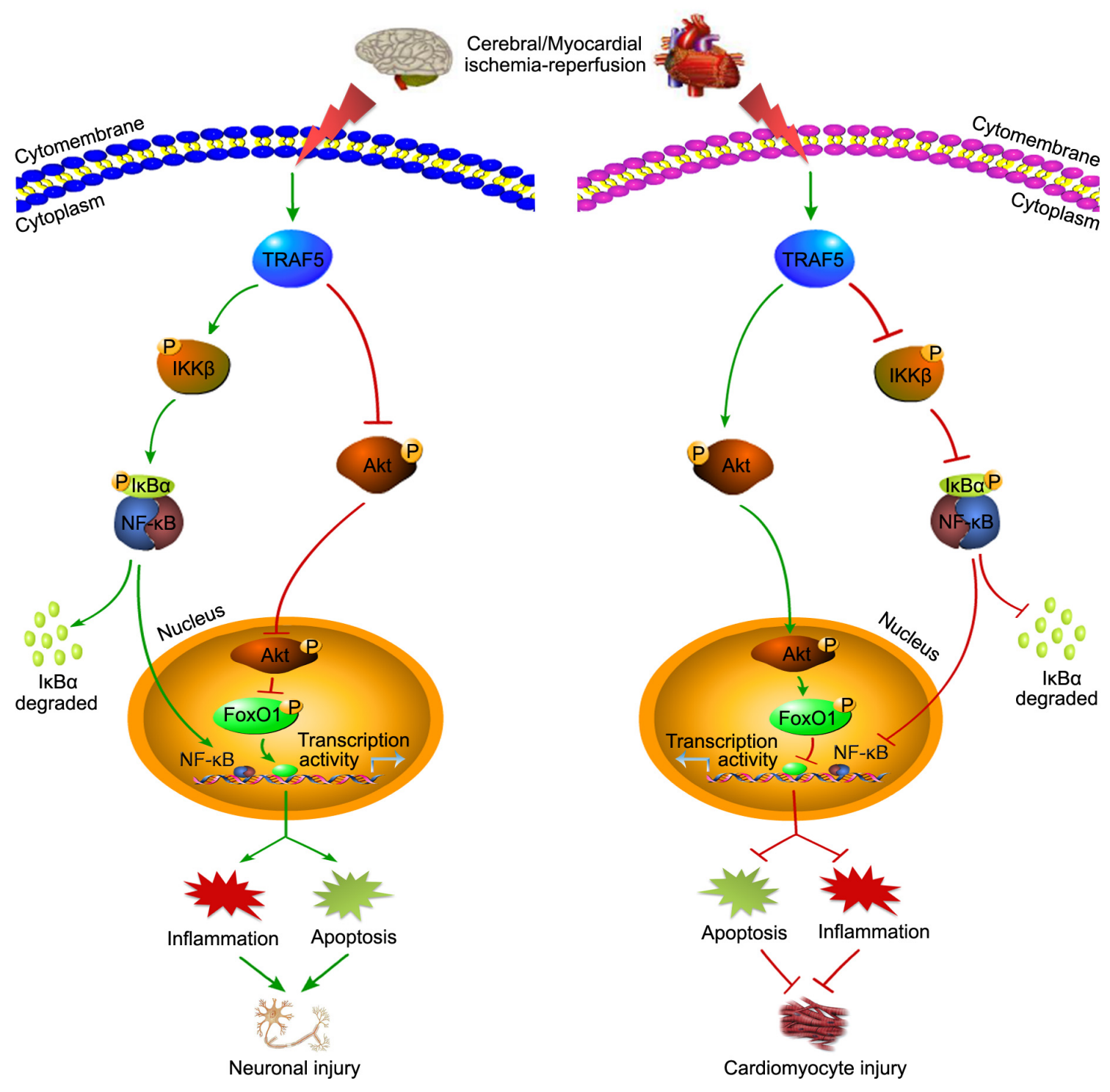

FIGURE 3 | The contradictory roles of TRAF5 in cerebral and myocardial IRI. TRAF5 is activated with cerebral and myocardial ischemia-reperfusion. Activated TRAF5 procedurally phosphorylates and promotes the NF-kB pathway and inhibits the Akt/FoxO1 pathway, which promotes the transcription activity of FoxO1, leading to neuronal injury via promoting inflammation and apoptosis. The contradictory effects of TRAF5 are present in cardiomyocytes.

inhibit TRAF6 to alleviate IRI of various organs, including the myocardia, kidney, intestine, and liver (Chen et al., 2013; Wang X. et al., 2013; Jiang et al., 2014; Dai et al., 2016; He et al., 2018). However, it is possible that TRAF6 was not significantly involved in the miR-146b/NF- $\kappa \mathrm{B}$ pathway in regulating liver IRI (Zhang et al., 2017). For IRI treatments other than drugs, other treatment strategies are also extremely important, such as ischemic preconditioning (IPC) and ischemic postconditioning (IPostC). A study has shown that IPC could inhibit the TLR4/TRAF6 pathway to alleviate intestinal IRI (Liu S. Z. et al., 2017). Analogously, limb remote ischemic postconditioning (LRIP) played a protective role in cerebral IRI by inhibiting the MyD88/TRAF6/p38-MAPK pathway (Chen et al., 2016). Therefore, the above studies have demonstrated that targeting the TRAF6 pathway may provide a clear direction and excellent effect for IRI treatment.

However, there is a major challenge for the treatment of lung IRI, a common disorder in patients with lung transplantation, resuscitation for circulatory arrest, cardiopulmonary bypass, and pulmonary embolism, due to the fact that its molecular mechanisms may be more complicated than other organs (Liu X. et al., 2017; Shen et al., 2018). Moreover, the lungs seem especially vulnerable to IRI because of their dual blood supply systems and higher physiological demand for gas exchange and oxygen uptake (Liu X. et al., 2017). Fortunately, studies have shown that reducing the K63-linked ubiquitination of TRAF6 and inhibition of the downstream NF- $\kappa$ B and MAPK pathways could relieve the inflammatory response amplified by autophagy 


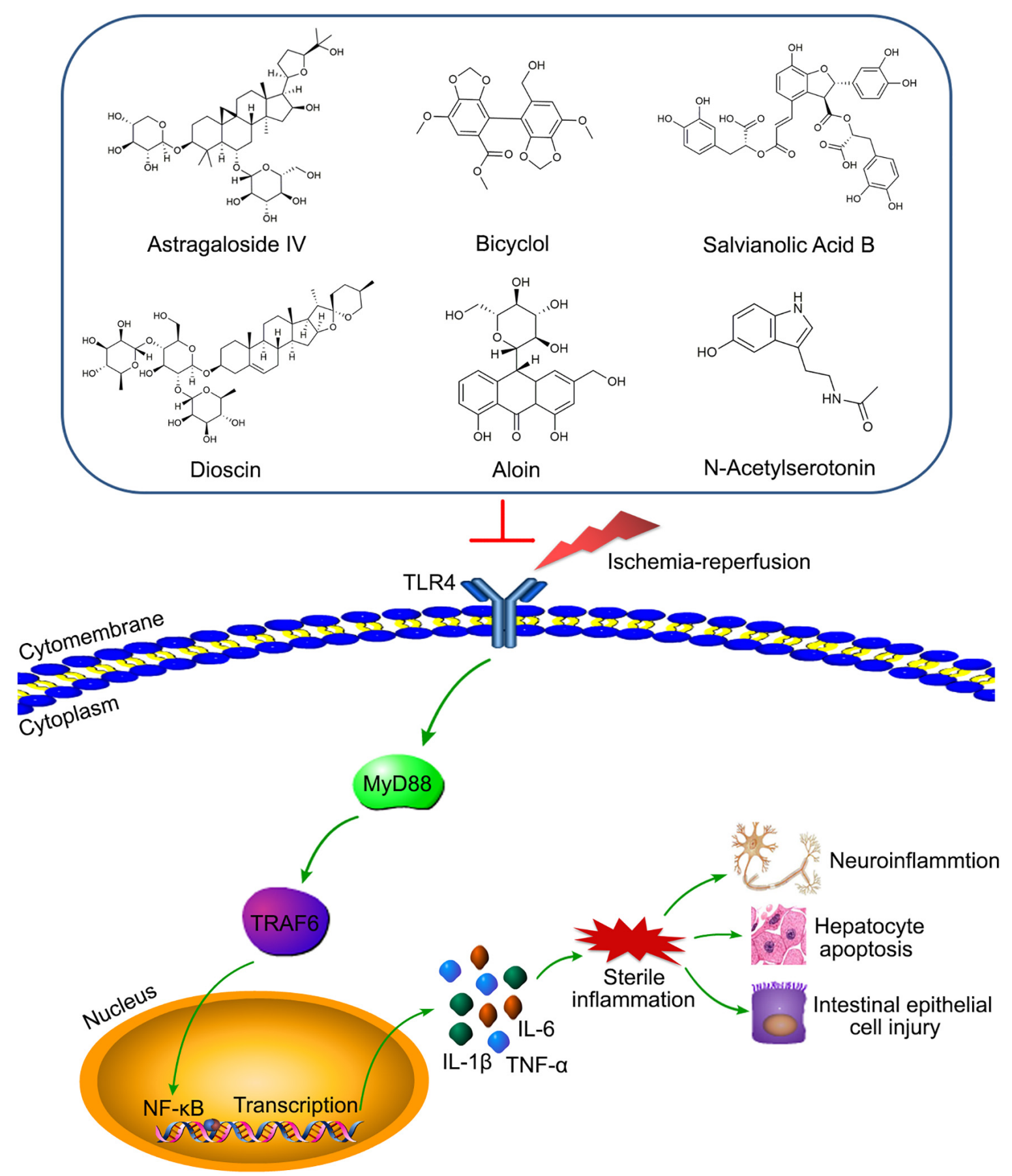

FIGURE 4 | Various compounds target TLR4/MyD88/TRAF6/NF-kB axis to alleviate IRI of diverse organs. Astragaloside IV (AS-IV), bicyclol, salvianolic acid B (SAB), and dioscin relieve the neuro-inflammation by inhibiting the axis. Aloin and N-Acetylserotonin (NAS) reduce hepatocyte apoptosis and intestinal epithelial cell injury via targeting the axis, respectively.

in lung IRI (Liu X. et al., 2017; Shen et al., 2018), suggesting that the ubiquitinated activation of TRAF6 and its management of autophagy are important underlying molecular mechanisms in lung IRI. Similarly, inhibition of the E3 ligase activity of TRAF6 significantly reduced cerebral and liver IRI (Li T. et al., 2017; Liu et al., 2020). Interestingly, TRAF6 could be inhibited by human mesenchymal stem cells (hMSCs)-derived exosomes, a kind of microvesicle with a diameter of about 30-100 nm, thereby reducing autophagy and apoptosis, playing a protective role in myocardial IRI (Jiang et al., 2018). Given all the above factors, we believe that the biological functions of TRAF6 and its related signaling pathways play a fatal role in the process of IRI. 
TABLE 1 | Genetic alterations of TRAF molecules in IRI or H/R models.

\begin{tabular}{|c|c|c|c|c|c|}
\hline TRAFs & IRI or H/R & Mice or cells genotype & Disease phenotype & Signaling pathways & References \\
\hline \multirow[t]{3}{*}{ TRAF1 } & $\begin{array}{l}\text { Cerebral } \mathrm{IRI} \text { or } \mathrm{H} / \mathrm{R} \text { of } \\
\text { primary neurons }\end{array}$ & $\begin{array}{l}\text { Mice: neuron-specific TG-TRAF1; } \\
\text { TRAF1-KO; Cells: Ad-TRAF1; } \\
\text { Ad-shTRAF1 }\end{array}$ & $\begin{array}{l}\text { TRAF1 enlarged ischemic lesions and } \\
\text { elevated neuronal apoptosis. }\end{array}$ & TRAF1/ASK1 & Lu et al., 2013 \\
\hline & $\begin{array}{l}\text { Liver IRI or } \mathrm{H} / \mathrm{R} \text { of } \\
\text { primary hepatocyte or } \\
\text { AML12 cells }\end{array}$ & $\begin{array}{l}\text { Mice: hepatocyte-specific } \\
\text { TG-TRAF1; TRAF1-KO; Cells: } \\
\text { Ad-shTRAF1; Ad-TRAF1; } \\
\text { pcDNA-TRAF1 }\end{array}$ & $\begin{array}{l}\text { TRAF1 aggravated liver histological } \\
\text { injury, increased serum ALT/AST levels, } \\
\text { and promoted cell apoptosis and } \\
\text { inflammation. }\end{array}$ & $\begin{array}{l}\text { TRAF1/ASK1/JNK; } \\
\text { miR- } \\
\text { 214/TRAF1/ASK1/JNK }\end{array}$ & $\begin{array}{l}\text { Zhang et al., } \\
\text { 2014; Huang X. } \\
\text { et al., } 2019\end{array}$ \\
\hline & $\begin{array}{l}\text { Myocardial IRI or } \mathrm{H} / \mathrm{R} \text { of } \\
\text { primary cardiomyocytes }\end{array}$ & Mice: TRAF1-KO; Cells: Ad-TRAF1 & $\begin{array}{l}\text { TRAF1 aggravated the heart function, } \\
\text { and promoted inflammation, and } \\
\text { cardiomyocytes apoptosis. }\end{array}$ & TRAF1/ASK1/JNK/p38 & $\begin{array}{l}\text { Xu W. et al., } \\
2019\end{array}$ \\
\hline \multirow[t]{3}{*}{ TRAF2 } & Myocardial IRI & $\begin{array}{l}\text { Mice: } M H C-T R A F 2_{L C} \\
\text { MHC-TRAF2 }\end{array}$ & $\begin{array}{l}\text { MHC-TRAF2 } 2 \text { C mice had a lower LV } \\
\text { developed pressure, a lower CK } \\
\text { release, and a lower Evans blue dye. }\end{array}$ & TRAF2/NF-кB & $\begin{array}{l}\text { Burchfield } \\
\text { et al., 2010; } \\
\text { Tzeng et al., } \\
2014\end{array}$ \\
\hline & $\begin{array}{l}\text { Intestinal IRI or } \mathrm{H} / \mathrm{R} \text { of } \\
\text { Caco- } 2 \text { cells }\end{array}$ & $\begin{array}{l}\text { Cells: phospho-mutant TRAF2 } \\
\text { plasmids: TRAF2-S55A (abolish } \\
\text { phosphorylation); TRAF2-S55 } \\
\text { (mimic phosphorylation) }\end{array}$ & $\begin{array}{l}\text { TRAF2 Ser }{ }^{55} \text { phosphorylation reduced } \\
\text { cell apoptosis. }\end{array}$ & TRAF2/NF-кB/c-JUN & $\begin{array}{l}\text { Zhou W. et al., } \\
2017\end{array}$ \\
\hline & $\begin{array}{l}\text { Cerebral IRI or } \mathrm{H} / \mathrm{R} \text { of } \\
\text { primary microglia and } \\
\text { neurons or HT-cells }\end{array}$ & $\begin{array}{l}\text { Mice: TRAF2 shRNA lentivirus; } \\
\text { Cells: TRAF2 shRNA lentivirus for } \\
\text { HT-cells or TRAF2 siRNA plasmid } \\
\text { for microglia }\end{array}$ & $\begin{array}{l}\text { TRAF2 knockdown increased } \\
\text { neuroinflammation, infarct volumes, and } \\
\text { the necroptosis of microglial and } \\
\text { HT-cells but reduced neuronal } \\
\text { apoptosis. }\end{array}$ & $\begin{array}{l}\text { TRAF2/MLKL; } \\
\text { Sphk1/TRAF2/NF-кB }\end{array}$ & $\begin{array}{l}\text { Su et al., 2017; } \\
\text { Li et al., 2019b }\end{array}$ \\
\hline \multirow[t]{4}{*}{ TRAF3 } & $\begin{array}{l}\text { Cerebral } \mathrm{IRI} \text { or } \mathrm{H} / \mathrm{R} \text { of } \\
\text { primary neurons }\end{array}$ & 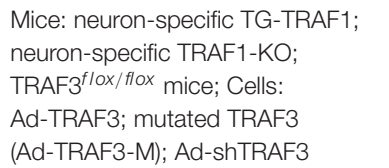 & $\begin{array}{l}\text { TRAF3 aggravated neuronal loss, } \\
\text { enlarged infarcts and promoted } \\
\text { neuronal apoptosis. }\end{array}$ & TRAF3/TAK1 & $\begin{array}{l}\text { Gong et al., } \\
2015\end{array}$ \\
\hline & $\begin{array}{l}\text { Liver } \mathrm{IRI} \text { or } \mathrm{H} / \mathrm{R} \text { of } \\
\text { primary hepatocyte }\end{array}$ & $\begin{array}{l}\text { Mice: hepatocyte-specific TRAF3 } \\
\text { knockout (TRAF3-LKO); myeloid } \\
\text { cell-specific TRAF3 knockout mice } \\
\text { (LysM-TRAF3-KO); } \\
\text { hepatocyte-specific TRAF3-TG } \\
\text { (TRAF3-LTG); TRAF3 }{ }^{\text {flox/flox mice; }} \\
\text { Ad-TRAF3; Ad-TRAF3-M; Cells: } \\
\text { Ad-TRAF3; Ad-TRAF3-M }\end{array}$ & $\begin{array}{l}\text { TRAF3 aggravated liver histological } \\
\text { injury, increased serum ALT/AST levels, } \\
\text { and promoted inflammation and cell } \\
\text { death. }\end{array}$ & $\begin{array}{l}\text { TRAF3/TAK1/JNK/NF- } \\
\kappa B\end{array}$ & Hu et al., 2016 \\
\hline & $\begin{array}{l}\text { Myocardial IRI or } \mathrm{H} / \mathrm{R} \text { of } \\
\text { primary cardiomyocytes }\end{array}$ & $\begin{array}{l}\text { Mice: TRAF3 siRNA in vivo } \\
\text { transfection; Cells: TRAF3 siRNA }\end{array}$ & $\begin{array}{l}\text { TRAF3 knockdown reduced the } \\
\text { infarction, attenuated cardiac } \\
\text { histological, decreased CK-MB release, } \\
\text { and alleviated cell apoptosis, } \\
\text { inflammation and oxidative stress. }\end{array}$ & TRAF3/JNK & $\begin{array}{l}\text { Liu X. et al., } \\
2018\end{array}$ \\
\hline & $\begin{array}{l}\text { Intestinal IRI or } \mathrm{H} / \mathrm{R} \text { of } \\
\text { IEC- } 6 \text { cells }\end{array}$ & $\begin{array}{l}\text { Cells: TRAF3 overexpression and } \\
\text { siRNA plasmid }\end{array}$ & $\begin{array}{l}\text { TRAF3 promoted inflammation and cell } \\
\text { apoptosis. }\end{array}$ & miR-29b-3p/TRAF3 & Dai et al., 2019 \\
\hline \multirow[t]{2}{*}{ TRAF5 } & Cerebral IRI & $\begin{array}{l}\text { Mice: neuron-specific TG-TRAF5; } \\
\text { TRAF5-KO }\end{array}$ & $\begin{array}{l}\text { TRAF5 aggravated BBB disruption, } \\
\text { augmented infract volumes, increased } \\
\text { neuronal apoptosis inflammatory } \\
\text { response. }\end{array}$ & TRAF5/Akt/FoxO1 & $\begin{array}{l}\text { Wang L. et al., } \\
2013\end{array}$ \\
\hline & $\begin{array}{l}\text { Myocardial IRI or H/R of } \\
\text { primary cardiomyocytes }\end{array}$ & Mice:TRAF5-KO Cells:Ad-TRAF5 & $\begin{array}{l}\text { TRAF5 relieved infract size, improved } \\
\text { cardiac dysfunction, reduced } \\
\text { cardiomyocytes apoptosis inflammatory } \\
\text { response. }\end{array}$ & TRAF5/Akt & Xu et al., 2020 \\
\hline \multirow[t]{4}{*}{ TRAF6 } & $\begin{array}{l}\text { Liver IRI or } \mathrm{H} / \mathrm{R} \text { of } \\
\text { RAW264.7 cells }\end{array}$ & Cells: TRAF6 siRNA & $\begin{array}{l}\text { TRAF6 silencing reduced } \\
\text { proinflammatory cytokine production. }\end{array}$ & $\begin{array}{l}\text { miR- } \\
\text { 146a/TRAF6/IRAK1 }\end{array}$ & $\begin{array}{l}\text { Wang X. et al., } \\
2013\end{array}$ \\
\hline & $\begin{array}{l}\text { Cerebral IRI or } \mathrm{H} / \mathrm{R} \text { of } \\
\text { primary neurons }\end{array}$ & $\begin{array}{l}\text { Mice: neuron-specific TG-TRAF6; } \\
\text { neuron-specific TRAF6-KO; Cells: } \\
\text { Ad-TRAF6; Ad-TRAF6-M; } \\
\text { Ad-shTRAF6 }\end{array}$ & $\begin{array}{l}\text { TRAF6 increased infract volumes, } \\
\text { neurological deficit scores, promoted } \\
\text { inflammation, oxidative stress and cell } \\
\text { apoptosis. }\end{array}$ & TRAF6/Rac1 & Li T. et al., 2017 \\
\hline & $\mathrm{H} / \mathrm{R}$ of IEC- 6 cells & Cells: Ad-TRAF6 & $\begin{array}{l}\text { Overexpression of TRAF6 promoted } \\
\text { cell apoptosis. }\end{array}$ & $\begin{array}{l}\text { miR- } \\
\text { 146a/TLR4/TRAF6/NF- } \\
\text { кB }\end{array}$ & He et al., 2018 \\
\hline & $\begin{array}{l}\text { Myocardial IRI or } \mathrm{H} / \mathrm{R} \text { of } \\
\mathrm{HCM} \text { cells }\end{array}$ & Cells: pcDNA3.1-TRAF6 & $\begin{array}{l}\text { Overexpression of TRAF6 promoted } \\
\text { inflammatory response cell apoptosis. }\end{array}$ & $\begin{array}{l}\text { IncRNA ROR/miR-124- } \\
\text { 3p/TRAF6 }\end{array}$ & $\begin{array}{l}\text { Liang et al., } \\
2019\end{array}$ \\
\hline
\end{tabular}




\section{CONCLUSION}

IRI is a common pathological process which occurs frequently in ischemic stroke, surgical treatment such as resection and transplant, thromboembolic events, and various other clinic events requiring the restoration of blood supply after ischemia, causing serious damage to various organs and even tissues throughout the body, thereby leading to a poor prognosis and high mortality. However, the pathogenesis of IRI is extremely complicated and varies in each organ, which brings enormous challenges to its treatment.

Explosive oxidative stress and inflammation response caused by various abnormal stimuli are common in the pathological process of IRI. Excessive accumulation of reactive oxygen species (ROS) and reactive nitrogen species are important pathological factors causing IRI in various organs, including retina, cerebral, myocardial, liver, kidney, lung and intestine (Jia et al., 2019, 2020; Li et al., 2020; Li et al., 2019d; Lonati et al., 2019; Qin et al., 2019; Yi et al., 2020). Oxidative stress may promote the expression of pro-inflammatory regulatory factors, and inflammatory cells may similarly induce the overproduction of ROS, thus forming a vicious circle to promote the occurrence and development of various diseases, including IRI. TRAFs are important mediators of inflammatory signaling and ROS regulation. For example, TRAF2 and TRAF6 are major components of ASK1 signalosome, which is very sensitive to oxidative stress and promote subsequent apoptosis (Noguchi et al., 2005; Sakauchi et al., 2017). Moreover, TRAF1 knockout effectively alleviate acute lung injury via inhibiting oxidative stress, inflammation and apoptosis (Bin et al., 2019). Further, as the adaptor proteins and the RING type E3 ubiquitin ligases, the TRAF family plays an indispensable role in the pathogenesis of IRI. The functions and activations of TRAFs are complex. Commonly, TRAFs are now recognized to be involved in a variety of signal cascades and act as central regulators of inflammation and immunity, including innate immune and adaptive immune. For instance, as the three main pattern recognition receptors (PRRs) of the innate immune system, TLRs, RLRs, and NLRs recruit TRAFs via MyD88 or TRIF, MAVS, and RIP2, respectively (Xie, 2013). TRAFs thereby regulates the downstream signaling pathways, including NF- $\mathrm{B}, \mathrm{MAPK}$ and interferon-regulatory factors (IRFs) pathways, to exert different biological effects, such as apoptosis, autophagy, necroptosis, and ferroptosis (Xie, 2013), which are fatal pathological processes in IRI.

Based on current research, we and other researchers have confirmed that most members of the TRAF family, except TRAF4 and TRAF7, play important roles in IRI by regulating different physiological mechanisms, including apoptosis, autophagy, necroptosis, and ferroptosis. Although TRAF proteins possess a similar structure, for IRI in diverse organs, each TRAF member exerts different effects by regulating different mechanisms, and even the same TRAF protein may cause different effects in different context. Visibly, TRAF2 knockdown increased the necroptosis of microglial and HT-cells under ischemic condition, but reduced neuronal apoptosis-induced by OGDR. Moreover, TRAF5 appeared to have a contradictory role in regulating cerebral and myocardial IRI. Therefore, TRAF proteins may exert different effects depending on the cell type and context-specific. Through gain and loss of function approaches, many studies have confirmed the definite molecular signaling pathways and effects of different TRAF members in regulating IRI of various organs, and the results have been summarized in Table 1, which showed that deletion or overexpression of TRAF molecules can cause obvious phenotypic differences in the models of various IRI, both in vivo and in vitro. In summary, the content presented in this review provides a compelling theoretical basis for IRI research and suggests clear targets for the treatment of IRIrelated diseases.

\section{PERSPECTIVES}

IRI is extremely common in clinical treatment and can cause serious consequences. Although many studies have shown that some treatments, such as IPC and IPostC, could improve IRI, there is still a lack of precise treatment strategies in the clinical setting currently. The points presented in this review indicated that TRAFs have an important influence in the development of IRI. Manipulation of TRAF proteins or the molecular pathways they regulate can provide new ideas for the treatment of IRI-related diseases. In fact, studies have shown that IPC and LRIP could significantly improve intestinal and cerebral IRI by targeting TRAF6 pathways (Chen et al., 2016; Liu S. Z. et al., 2017). In addition, a recent study showed preactivated and disaggregated shape-changed platelet (PreDSCP) therapy effectively reduced the renal IRI by inhibiting the TLR4/MyD88/TRAF6 signaling pathway (Chen et al., 2019). In addition to the research on treatment methods, small agonists and antagonists targeting TRAFs have also became a focus in recent years. Numerous studies have shown that different miRNAs could reverse the effects of targeting respective TRAFs and reduce the IRI of various organs, including the liver, heart, intestine, kidney, and retina (Dai et al., 2016, 2019; Huang Z. et al., 2019; Liang et al., 2019; Ge et al., 2020). Moreover, many drugs or compounds played a protective role in IRI by targeting the TRAFs pathways. Illustratively, tauroursodeoxycholic acid (TUDCA), a classical conjugated bile acid, can effectively alleviate liver IRI via inhibiting IRE1 $\alpha /$ TRAF2/NF- $\mathrm{B}$ pathway activity (Xu et al., 2018). Furthermore, AS-IV, bicyclol, SAB, and dioscin all played protective roles in cerebral IRI by inhibiting the TLR4/MyD88/TRAF6/NF- $\kappa$ B axis (Zhang et al., 2013; Tao et al., 2015; Wang et al., 2016; Li M. et al., 2017; Figure 4). Additionally, the latest research showed that TRAF6 was also involved in the regulation of aloin and NAS preconditioning to reduce liver and intestinal IRI, respectively (Du et al., 2019; Sukhotnik et al., 2019; Figure 4). The above research indicated that TRAFs have received much attention in the treatment of IRI, and new treatment methods and related mechanisms have been continuously discovered. However, the targets of TRAF proteins in various organs and the signaling pathways they regulate are variational; even TRAF proteins may have opposite effects in different organs, which brings great obstacles to the research of drugs or strategies for the treatment to IRI-related diseases. Moreover, it is still unclear whether TRAF4 or TRAF7 could also 
play an important role in IRI like other TRAF members, and what kind of specific role they would play. Therefore, the role of TRAFs in IRI needs more in-depth studies in the future.

\section{AUTHOR CONTRIBUTIONS}

WZ and QY formulated the conception of this review. WZ and DL co-wrote the manuscript. ZZ and QY

\section{REFERENCES}

Abdul-Sater, A. A., Edilova, M. I., Clouthier, D. L., Mbanwi, A., Kremmer, E., and Watts, T. H. (2017). The signaling adaptor TRAF1 negatively regulates Tolllike receptor signaling and this underlies its role in rheumatic disease. Nat. Immunol. 18, 26-35. doi: 10.1038/ni.3618

Anto Michel, N., Colberg, C., Buscher, K., Sommer, B., Pramod, A. B., Ehinger, E., et al. (2018). Inflammatory pathways regulated by tumor necrosis receptorassociated factor 1 protect from metabolic consequences in diet-induced obesity. Circ. Res. 122, 693-700. doi: 10.1161/circresaha.117.312055

Arkee, T., and Bishop, G. A. (2019). TRAF family molecules in T cells: multiple receptors and functions. J. Leukoc. Biol. 107, 907-915. doi: 10.1002/JLB. 2MR1119-397R

Bajwa, A., Huang, L., Kurmaeva, E., Gigliotti, J. C., Ye, H., Miller, J., et al. (2016). Sphingosine 1-phosphate receptor 3-deficient dendritic cells modulate splenic responses to ischemia-reperfusion injury. J. Am. Soc. Nephrol. 27, 1076-1090. doi: 10.1681/asn.2015010095

Ben Mkaddem, S., Pedruzzi, E., Werts, C., Coant, N., Bens, M., Cluzeaud, F., et al. (2010). Heat shock protein gp96 and NAD(P)H oxidase 4 play key roles in Tolllike receptor 4-activated apoptosis during renal ischemia/reperfusion injury. Cell Death Differ. 17, 1474-1485. doi: 10.1038/cdd.2010.26

Bhat, E. A., Kim, C. M., Kim, S., and Park, H. H. (2018). In vitro inhibitory mechanism effect of TRAIP on the function of TRAF2 revealed by characterization of interaction domains. Int. J. Mol. Sci. 19:2457. doi: 10.3390/ ijms 19082457

Bian, Z., Dai, J., Hiroyasu, N., Guan, H., Yuan, Y., Gan, L., et al. (2014). Disruption of tumor necrosis factor receptor associated factor 5 exacerbates pressure overload cardiac hypertrophy and fibrosis. J. Cell. Biochem. 115, 349-358. doi: $10.1002 /$ jcb. 24669

Bin, W., Ming, X., and Wen-Xia, C. (2019). TRAF1 meditates lipopolysaccharideinduced acute lung injury by up regulating JNK activation. Biochem. Biophys. Res. Commun. 511, 49-56. doi: 10.1016/j.bbrc.2019.01.041

Bista, P., Zeng, W., Ryan, S., Bailly, V., Browning, J. L., and Lukashev, M. E. (2010). TRAF3 controls activation of the canonical and alternative NFkappaB by the lymphotoxin beta receptor. J. Biol. Chem. 285, 12971-12978. doi: 10.1074/jbc. M109.076091

Burchfield, J. S., Dong, J. W., Sakata, Y., Gao, F., Tzeng, H. P., Topkara, V. K., et al. (2010). The cytoprotective effects of tumor necrosis factor are conveyed through tumor necrosis factor receptor-associated factor 2 in the heart. Circ. Heart Fail. 3, 157-164. doi: 10.1161/circheartfailure.109.899732

Cai, S., Huang, Y., Wang, B., Jian, J., and Xu, Y. (2017). Tumor necrosis factor receptor-associated factor 6 (TRAF6) participates in peroxinectin gene expression in Fenneropenaeus penicillatus. Fish Shellfish Immunol. 64, 193-201. doi: $10.1016 /$ j.fsi.2017.03.026

Chen, G., Ye, X., Zhang, J., Tang, T., Li, L., Lu, P., et al. (2016). Limb remote ischemic postconditioning reduces ischemia-reperfusion injury by inhibiting NADPH oxidase activation and MyD88-TRAF6-P38MAP-kinase pathway of neutrophils. Int. J. Mol. Sci. 17:1971. doi: 10.3390/ijms17121971

Chen, K., Xu, Z., Liu, Y., Wang, Z., Li, Y., Xu, X., et al. (2017). Irisin protects mitochondria function during pulmonary ischemia/reperfusion injury. Sci. Transl. Med. 9:eaao6298. doi: 10.1126/scitranslmed.aao6298

Chen, Q., Kong, L., Xu, X., Geng, Q., Tang, W., and Jiang, W. (2013). Downregulation of microRNA-146a in the early stage of liver ischemia-reperfusion injury. Transplant Proc. 45, 492-496. doi: 10.1016/j.transproceed.2012.10.045 revised the manuscript. All authors read and approved the final manuscript.

\section{FUNDING}

This work was supported by the National Natural Science Foundation of China (Grant Nos. 81970548, 81570079, and 81700657).

Chen, S., Yang, J., Yang, L., Zhang, Y., Zhou, L., Liu, Q., et al. (2018). Ubiquitin ligase TRAF2 attenuates the transcriptional activity of the core clock protein BMAL1 and affects the maximal Perl mRNA level of the circadian clock in cells. FEBS J. 285, 2987-3001. doi: 10.1111/febs. 14595

Chen, S. Y., Zhang, H. P., Li, J., Shi, J. H., Tang, H. W., Zhang, Y., et al. (2020). Tripartite motif-containing 27 attenuates liver ischemia/reperfusion injury by suppressing TAK1 via TAB2/3 degradation. Hepatology [Epub ahead of print]. doi: 10.1002/hep.31295

Chen, Y. T., Yang, C. C., Lin, K. C., Chen, K. H., Sung, P. H., Shao, P. L., et al. (2019). Preactivated and disaggregated shape-changed platelets protect kidney against from ischemia-reperfusion injury in rat through attenuating inflammation reaction. J. Tissue Eng. Regen. Med. 13, 2155-2168. doi: 10.1002/term.2960

Choi, Y. B., Choi, Y., and Harhaj, E. W. (2018). Peroxisomes support human herpesvirus 8 latency by stabilizing the viral oncogenic protein vFLIP via the MAVS-TRAF complex. PLoS Pathog. 14:e1007058. doi: 10.1371/journal.ppat. 1007058

Clark, V. E., Erson-Omay, E. Z., Serin, A., Yin, J., Cotney, J., Ozduman, K., et al. (2013). Genomic analysis of non-NF2 meningiomas reveals mutations in TRAF7, KLF4, AKT1, and SMO. Science 339, 1077-1080. doi: 10.1126/science. 1233009

da Silva, S. D., Xu, B., Maschietto, M., Marchi, F. A., Alkailani, M. I., Bijian, K., et al. (2019). TRAF2 cooperates with focal adhesion signaling to regulate cancer cell susceptibility to anoikis. Mol. Cancer Ther. 18, 139-146. doi: 10.1158/15357163.MCT-17-1261

Dai, Y., Jia, P., Fang, Y., Liu, H., Jiao, X., He, J. C., et al. (2016). miR-146a is essential for lipopolysaccharide (LPS)-induced cross-tolerance against kidney ischemia/reperfusion injury in mice. Sci. Rep. 6:27091. doi: 10.1038/srep27091

Dai, Y., Mao, Z., Han, X., Xu, Y., Xu, L., Yin, L., et al. (2019). MicroRNA$29 \mathrm{~b}-3 \mathrm{p}$ reduces intestinal ischaemia/reperfusion injury via targeting of TNF receptor-associated factor 3. Br. J. Pharmacol. 176, 3264-3278. doi: 10.1111/ bph.14759

Das, A., Sudhahar, V., Ushio-Fukai, M., and Fukai, T. (2019). Novel interaction of antioxidant-1 with TRAF4: role in inflammatory responses in endothelial cells. Am. J. Physiol. Cell Physiol. 317, C1161-C1171. doi: 10.1152/ajpcell.00264.2019

David, L., Li, Y., Ma, J., Garner, E., Zhang, X., and Wu, H. (2018). Assembly mechanism of the CARMA1-BCL10-MALT1-TRAF6 signalosome. Proc. Natl. Acad. Sci. U.S.A. 115, 1499-1504. doi: 10.1073/pnas.1721967115

Dhillon, B., Aleithan, F., Abdul-Sater, Z., and Abdul-Sater, A. A. (2019). The evolving role of TRAFs in mediating inflammatory responses. Front. Immunol. 10:104. doi: 10.3389/fimmu.2019.00104

Du, Y., Qian, B., Gao, L., Tan, P., Chen, H., Wang, A., et al. (2019). Aloin preconditioning attenuates hepatic ischemia/reperfusion injury via inhibiting TLR4/MyD88/NF-kappaB signal pathway in vivo and in vitro. Oxid. Med. Cell. Longev. 2019:3765898. doi: 10.1155/2019/3765898

Fang, R., Jiang, Q., Zhou, X., Wang, C., Guan, Y., Tao, J., et al. (2017). MAVS activates TBK1 and IKKepsilon through TRAFs in NEMO dependent and independent manner. PLoS Pathog. 13:e1006720. doi: 10.1371/journal.ppat. 1006720

Fochi, S., Bergamo, E., Serena, M., Mutascio, S., Journo, C., Mahieux, R., et al. (2019). TRAF3 Is Required for NF-кB pathway activation mediated by HTLV tax proteins. Front. Microbiol. 10:1302. doi: 10.3389/fmicb.2019.01302

Foight, G. W., and Keating, A. E. (2016). Comparison of the peptide binding preferences of three closely related TRAF paralogs: TRAF2, TRAF3, and TRAF5. Protein Sci. 25, 1273-1289. doi: 10.1002/pro.2881 
Fu, T. M., Shen, C., Li, Q., Zhang, P., and Wu, H. (2018). Mechanism of ubiquitin transfer promoted by TRAF6. Proc. Natl. Acad. Sci. U.S.A. 115, 1783-1788. doi: 10.1073/pnas.1721788115

Gao, L., Wang, P. X., Zhang, Y., Yu, C. J., Ji, Y., Wang, X., et al. (2016). Tumor necrosis factor receptor-associated factor 5 (Traf5) acts as an essential negative regulator of hepatic steatosis. J. Hepatol. 65, 125-136. doi: 10.1016/j.jhep.2016. 03.006

Gao, M., Monian, P., Quadri, N., Ramasamy, R., and Jiang, X. (2015). Glutaminolysis and transferrin regulate ferroptosis. Mol. Cell. 59, 298-308. doi: 10.1016/j.molcel.2015.06.011

Ge, Y., Zhang, R., Feng, Y., and Li, H. (2020). Mbd2 mediates retinal cell apoptosis by targeting the IncRNA Mbd2-AL1/miR-188-3p/Traf3 axis in ischemia/reperfusion injury. Mol. Ther. Nucleic Acids 19, 1250-1265. doi: 10. 1016/j.omtn.2020.01.011

Gigliotti, J. C., Huang, L., Ye, H., Bajwa, A., Chattrabhuti, K., Lee, S., et al. (2013). Ultrasound prevents renal ischemia-reperfusion injury by stimulating the splenic cholinergic anti-inflammatory pathway. J. Am. Soc. Nephrol. 24, 1451-1460. doi: 10.1681/asn.2013010084

Gong, J., Li, Z. Z., Guo, S., Zhang, X. J., Zhang, P., Zhao, G. N., et al. (2015). Neuron-specific tumor necrosis factor receptor-associated factor 3 is a central regulator of neuronal death in acute ischemic stroke. Hypertension 66, 604-616. doi: 10.1161/hypertensionaha.115.05430

Goode, B., Joseph, N. M., Stevers, M., Van Ziffle, J., Onodera, C., Talevich, E., et al. (2018). Adenomatoid tumors of the male and female genital tract are defined by TRAF7 mutations that drive aberrant NF-kB pathway activation. Mod. Pathol. 31, 660-673. doi: 10.1038/modpathol.2017.153

Gu, Z., Shi, W., Zhang, L., Hu, Z., and Xu, C. (2017). USP19 suppresses cellular type I interferon signaling by targeting TRAF3 for deubiquitination. Future Microbiol. 12, 767-779. doi: 10.2217/fmb-2017-2016

Guo, X., Yin, H., Li, L., Chen, Y., Li, J., Doan, J., et al. (2017). Cardioprotective role of tumor necrosis factor receptor-associated factor 2 by suppressing apoptosis and necroptosis. Circulation 136, 729-742. doi: 10.1161/circulationaha.116. 026240

He, H., Wu, Z., Li, S., Chen, K., Wang, D., Zou, H., et al. (2020). TRAF7 enhances ubiquitin-degradation of KLF4 to promote hepatocellular carcinoma progression. Cancer Lett. 469, 380-389. doi: 10.1016/j.canlet.2019.11.012

He, L., Grammer, A. C., Wu, X., and Lipsky, P. E. (2004). TRAF3 forms heterotrimers with TRAF2 and modulates its ability to mediate NF-кB activation. J. Biol. Chem. 279, 55855-55865. doi: 10.1074/jbc.M4 07284200

He, X., Zheng, Y., Liu, S., Shi, S., Liu, Y., He, Y., et al. (2018). MiR-146a protects small intestine against ischemia/reperfusion injury by down-regulating TLR4/TRAF6/NF-kB pathway. J. Cell. Physiol. 233, 2476-2488. doi: 10.1002/jcp. 26124

Higuchi, S., Wu, R., Zhou, M., Marini, C. P., Ravikumar, T. S., and Wang, P. (2008). Gut hyperpermiability after ischemia and reperfusion: attenuation with adrenomedullin and its binding protein treatment. Int. J. Clin. Exp. Pathol. 1, 409-418.

Hirsova, P., Guicciardi, M. E., and Gores, G. J. (2017). Proapoptotic signaling induced by deletion of receptor-interacting kinase 1 and TNF receptorassociated factor 2 results in liver carcinogenesis. Hepatology 66, 983-985. doi: 10.1002/hep.29272

Hu, J., Zhu, X. H., Zhang, X. J., Wang, P. X., Zhang, R., Zhang, P., et al. (2016). Targeting TRAF3 signaling protects against hepatic ischemia/reperfusions injury. J. Hepatol. 64, 146-159. doi: 10.1016/j.jhep.2015.08.021

Hu, L., Xu, J., Xie, X., Zhou, Y., Tao, P., Li, H., et al. (2017). Oligomerizationprimed coiled-coil domain interaction with Ubc13 confers processivity to TRAF6 ubiquitin ligase activity. Nat. Commun. 8:814. doi: 10.1038/s41467-01 7-01290-0

Huang, X., Gao, Y., Qin, J., and Lu, S. (2019). miR-214 down-regulation promoted hypoxia/reoxygenation-induced hepatocyte apoptosis through TRAF1/ASK1/JNK pathway. Dig. Dis. Sci. 64, 1217-1225. doi: $10.1007 / \mathrm{s} 10620-018-5405-9$

Huang, Z., Zheng, D., Pu, J., Dai, J., Zhang, Y., Zhang, W., et al. (2019). MicroRNA$125 \mathrm{~b}$ protects liver from ischemia/reperfusion injury via inhibiting TRAF6 and NF-кB pathway. Biosci. Biotechnol. Biochem. 83, 829-835. doi: 10.1080/ 09168451.2019 .1569495
Hui, Q., Karlstetter, M., Xu, Z., Yang, J., Zhou, L., Eilken, H. M., et al. (2020). Inhibition of the Keap1-Nrf2 protein-protein interaction protects retinal cells and ameliorates retinal ischemia-reperfusion injury. Free Radic. Biol. Med. 146, 181-188. doi: 10.1016/j.freeradbiomed.2019.10.414

Ivagnès, A., Messaoudene, M., Stoll, G., Routy, B., Fluckiger, A., Yamazaki, T., et al. (2018). TNFR2/BIRC3-TRAF1 signaling pathway as a novel NK cell immune checkpoint in cancer. Oncoimmunology 7:e1386826. doi: 10.1080/2162402x. 2017.1386826

Jia, P., Wu, X., Pan, T., Xu, S., Hu, J., and Ding, X. (2019). Uncoupling protein 1 inhibits mitochondrial reactive oxygen species generation and alleviates acute kidney injury. EBioMedicine 49, 331-340. doi: 10.1016/j.ebiom.2019.10.023

Jia, Y., Cui, R., Wang, C., Feng, Y., Li, Z., Tong, Y., et al. (2020). Metformin protects against intestinal ischemia-reperfusion injury and cell pyroptosis via TXNIPNLRP3-GSDMD pathway. Redox. Biol. 32:101534. doi: 10.1016/j.redox.2020. 101534

Jiang, S., Xiao, J., Li, J., Chen, H., Wang, C., Feng, C., et al. (2017). Characterization of the black carp TRAF6 signaling molecule in innate immune defense. Fish Shellfish Immunol. 67, 147-158. doi: 10.1016/j.fsi.2017.06.011

Jiang, W., Cheng, X., Wang, T., Song, X., Zheng, Y., and Wang, L. (2020). LINC00467 promotes cell proliferation and metastasis by binding with IGF2BP3 to enhance the mRNA stability of TRAF5 in hepatocellular carcinoma. J. Gene Med. 22:e3134. doi: 10.1002/jgm.3134

Jiang, W., Kong, L., Ni, Q., Lu, Y., Ding, W., Liu, G., et al. (2014). miR146a ameliorates liver ischemia/reperfusion injury by suppressing IRAK1 and TRAF6. PLoS One 9:e101530. doi: 10.1371/journal.pone.0101530

Jiang, X., Lew, K. S., Chen, Q., Richards, A. M., and Wang, P. (2018). Human mesenchymal stem cell-derived exosomes reduce ischemia/reperfusion injury by the inhibitions of apoptosis and autophagy. Curr. Pharm. Des. 24, 5334-5341. doi: 10.2174/1381612825666190119130441

Kang, Q., Zou, H., Zhou, L., Liu, L. X., Cai, J. B., Xie, N., et al. (2018). Role of the overexpression of TRAF4 in predicting the prognosis of intrahepatic cholangiocarcinoma. Int. J. Oncol. 53, 286-296. doi: 10.3892/ijo.2018.4383

Kim, C. M., Jang, H., Ha, H. J., Kim, G. E., and Park, H. H. (2020). Structural and biochemical characterization of TRAF5 from Notothenia coriiceps and its implications in fish immune cell signaling. Fish Shellfish Immunol. 102, 56-63. doi: $10.1016 /$ j.fsi.2020.04.016

Kim, C. M., Jeong, J. H., Son, Y. J., Choi, J. H., Kim, S., and Park, H. H. (2017). Molecular basis for TANK recognition by TRAF1 revealed by the crystal structure of TRAF1/TANK complex. FEBS Lett. 591, 810-821. doi: 10.1002/ 1873-3468.12584

Kim, E., Kim, W., Lee, S., Chun, J., Kang, J., Park, G., et al. (2017). TRAF4 promotes lung cancer aggressiveness by modulating tumor microenvironment in normal fibroblasts. Sci. Rep. 7:8923. doi: 10.1038/s41598-017-09447-z

Kim, H. Y., and Lee, S. M. (2012). Ferulic acid attenuates ischemia/reperfusioninduced hepatocyte apoptosis via inhibition of JNK activation. Eur. J. Pharm. Sci. 45, 708-715. doi: 10.1016/j.ejps.2012.01.010

Klein, C. J., Wu, Y., Jentoft, M. E., Mer, G., Spinner, R. J., Dyck, P. J., et al. (2017). Genomic analysis reveals frequent TRAF7 mutations in intraneural perineuriomas. Ann. Neurol. 81, 316-321. doi: 10.1002/ana.24854

Kohler, D., Granja, T., Volz, J., Koeppen, M., Langer, H. F., Hansmann, G., et al. (2020). Red blood cell-derived semaphorin 7A promotes thromboinflammation in myocardial ischemia-reperfusion injury through platelet GPIb. Nat. Commun. 11:1315. doi: 10.1038/s41467-020-14958-x

Lalani, A. I., Zhu, S., Gokhale, S., Jin, J., and Xie, P. (2018). TRAF molecules in inflammation and inflammatory diseases. Curr. Pharmacol. Rep. 4, 64-90. doi: 10.1007/s40495-017-0117-y

Lan, P., Fan, Y., Zhao, Y., Lou, X., Monsour, H. P., Zhang, X., et al. (2017). TNF superfamily receptor OX40 triggers invariant NKT cell pyroptosis and liver injury. J. Clin. Invest. 127, 2222-2234. doi: 10.1172/jci91075

Li, D., Wang, X., Huang, Q., Li, S., Zhou, Y., and Li, Z. (2018a). Cardioprotection of CAPE-oNO(2) against myocardial ischemia/reperfusion induced ROS generation via regulating the SIRT1/eNOS/NF- $\mathrm{KB}$ pathway in vivo and in vitro. Redox. Biol. 15, 62-73. doi: 10.1016/j.redox.2017.11.023

Li, J., Ayoub, A., Xiu, Y., Yin, X., Sanders, J. O., Mesfin, A., et al. (2019a). TGF $\beta$-induced degradation of TRAF3 in mesenchymal progenitor cells causes age-related osteoporosis. Nat. Commun. 10:2795. doi: 10.1038/s41467-01 9-10677-0 
Li, J., Zhang, J., Zhang, Y., Wang, Z., Song, Y., Wei, S., et al. (2019b). TRAF2 protects against cerebral ischemia-induced brain injury by suppressing necroptosis. Cell Death Dis. 10:328. doi: 10.1038/s41419-019-1558-5

Li, L., Wang, Y., Guo, R., Li, S., Ni, J., Gao, S., et al. (2020). Ginsenoside Rg3-loaded, reactive oxygen species-responsive polymeric nanoparticles for alleviating myocardial ischemia-reperfusion injury. J. Control. Release 317, 259-272. doi: 10.1016/j.jconrel.2019.11.032

Li, M., Khan, A. M., Maderdrut, J. L., Simon, E. E., and Batuman, V. (2010). The effect of PACAP38 on MyD88-mediated signal transduction in ischemia/hypoxia-induced acute kidney injury. Am. J. Nephrol. 32, 522-532. doi: 10. $1159 / 000321491$

Li, M., Li, H., Fang, F., Deng, X., and Ma, S. (2017). Astragaloside IV attenuates cognitive impairments induced by transient cerebral ischemia and reperfusion in mice via anti-inflammatory mechanisms. Neurosci. Lett. 639, 114-119. doi: 10.1016/j.neulet.2016.12.046

Li, P., Zhao, G., Ding, Y., Wang, T., Flores, J., Ocak, U., et al. (2019c). RhIFN- $\alpha$ attenuates neuroinflammation and improves neurological function by inhibiting NF-KB through JAK1-STAT1/TRAF3 pathway in an experimental GMH rat model. Brain Behav. Immun. 79, 174-185. doi: 10.1016/j.bbi.2019.01. 028

Li, S., Jiang, D., Ehlerding, E. B., Rosenkrans, Z. T., Engle, J. W., Wang, Y., et al. (2019d). Intrathecal administration of nanoclusters for protecting neurons against oxidative stress in cerebral ischemia/reperfusion injury. ACS Nano 13, 13382-13389. doi: 10.1021/acsnano.9b06780

Li, S., Jiang, D., Rosenkrans, Z. T., Barnhart, T. E., Ehlerding, E. B., Ni, D., et al. (2019e). Aptamer-conjugated framework nucleic acids for the repair of cerebral ischemia-reperfusion injury. Nano Lett. 19, 7334-7341. doi: 10.1021/ acs.nanolett.9b02958

Li, S., Wang, D., Zhao, J., Weathington, N. M., Shang, D., and Zhao, Y. (2018b). The deubiquitinating enzyme USP48 stabilizes TRAF2 and reduces E-cadherin-mediated adherens junctions. FASEB J. 32, 230-242. doi: 10.1096/ f. $201700415 R R$

Li, T., Qin, J. J., Yang, X., Ji, Y. X., Guo, F., Cheng, W. L., et al. (2017). The ubiquitin E3 ligase TRAF6 exacerbates ischemic stroke by ubiquitinating and activating Rac1. J. Neurosci. 37, 12123-12140. doi: 10.1523/JNEUROSCI.1751-17.2017

Li, X. Q., Yu, Q., Chen, F. S., Tan, W. F., Zhang, Z. L., and Ma, H. (2018c). Inhibiting aberrant p53-PUMA feedback loop activation attenuates ischaemia reperfusion-induced neuroapoptosis and neuroinflammation in rats by downregulating caspase 3 and the NF- $\mathrm{KB}$ cytokine pathway. J. Neuroinflamm. 15:250. doi: 10.1186/s12974-018-1271-9

Li, X., Yang, Y., and Ashwell, J. D. (2002). TNF-RII and c-IAP1 mediate ubiquitination and degradation of TRAF2. Nature 416, 345-347. doi: 10.1038/ 416345a

Li, Y., Feng, D., Wang, Z., Zhao, Y., Sun, R., Tian, D., et al. (2019f). Ischemiainduced ACSL4 activation contributes to ferroptosis-mediated tissue injury in intestinal ischemia/reperfusion. Cell Death Differ. 26, 2284-2299. doi: 10.1038/ s41418-019-0299-4

Li, Z., Wang, G., Feng, D., Zu, G., Li, Y., Shi, X., et al. (2018d). Targeting the miR-665-3p-ATG4B-autophagy axis relieves inflammation and apoptosis in intestinal ischemia/reperfusion. Cell Death Dis. 9:483. doi: 10.1038/s41419-0180518-9

Liang, Y. P., Liu, Q., Xu, G. H., Zhang, J., Chen, Y., Hua, F. Z., et al. (2019). The lncRNA ROR/miR-124-3p/TRAF6 axis regulated the ischaemia reperfusion injury-induced inflammatory response in human cardiac myocytes. J. Bioenerg. Biomembr. 51, 381-392. doi: 10.1007/s10863-019-09812-9

Ling, Z. A., Xiong, D. D., Meng, R. M., Cen, J. M., Zhao, N., Chen, G., et al. (2018). LncRNA NEAT1 promotes deterioration of hepatocellular carcinoma based on in vitro experiments, data mining, and RT-qPCR analysis. Cell Physiol. Biochem. 48, 540-555. doi: 10.1159/000491811

Linkermann, A., Bräsen, J. H., Himmerkus, N., Liu, S., Huber, T. B., Kunzendorf, U., et al. (2012). Rip1 (receptor-interacting protein kinase 1) mediates necroptosis and contributes to renal ischemia/reperfusion injury. Kidney Int. 81, 751-761. doi: 10.1038/ki.2011.450

Liu, F., Cheng, L., Xu, J., Guo, F., and Chen, W. (2018). miR-17-92 functions as an oncogene and modulates NF- $\mathrm{kB}$ signaling by targeting TRAF3 in MGC-803 human gastric cancer cells. Int. J. Oncol. 53, 2241-2257. doi: 10.3892/ijo.2018. 4543
Liu, H., Fan, J., Zhang, W., Chen, Q., Zhang, Y., and Wu, Z. (2020). OTUD4 alleviates hepatic ischemia-reperfusion injury by suppressing the K63-linked ubiquitination of TRAF6. Biochem. Biophys. Res. Commun. 523, 924-930. doi: 10.1016/j.bbrc.2019.12.114

Liu, S. Z., He, X. M., Zhang, X., Zeng, F. C., Wang, F., and Zhou, X. Y. (2017). Ischemic Preconditioning-Induced SOCS-1 Protects Rat Intestinal Ischemia Reperfusion Injury via Degradation of TRAF6. Dig. Dis. Sci. 62, 105-114. doi: 10.1007/s10620-016-4277-0

Liu, X., Cao, H., Li, J., Wang, B., Zhang, P., Dong Zhang, X., et al. (2017). Autophagy induced by DAMPs facilitates the inflammation response in lungs undergoing ischemia-reperfusion injury through promoting TRAF6 ubiquitination. Cell Death Differ. 24, 683-693. doi: 10.1038/cdd.2017.1

Liu, X., Zhang, L., Qin, H., Han, X., Zhang, Z., Zhang, Z., et al. (2018). Inhibition of TRAF3 expression alleviates cardiac ischemia reperfusion (IR) injury: A mechanism involving in apoptosis, inflammation and oxidative stress. Biochem. Biophys. Res. Commun. 506, 298-305. doi: 10.1016/j.bbrc.2018.10.058

Lonati, C., Bassani, G. A., Brambilla, D., Leonardi, P., Carlin, A., Maggioni, M., et al. (2019). Mesenchymal stem cell-derived extracellular vesicles improve the molecular phenotype of isolated rat lungs during ischemia/reperfusion injury. J. Heart Lung Transpl. 38, 1306-1316. doi: 10.1016/j.healun.2019. 08.016

Lu, C. H., Yeh, D. W., Lai, C. Y., Liu, Y. L., Huang, L. R., Lee, A. Y., et al. (2018). USP17 mediates macrophage-promoted inflammation and stemness in lung cancer cells by regulating TRAF2/TRAF3 complex formation. Oncogene 37, 6327-6340. doi: 10.1038/s41388-018-0411-0

Lu, W., Liu, S., Li, B., Xie, Y., Izban, M. G., Ballard, B. R., et al. (2017). SKP2 loss destabilizes EZH2 by promoting TRAF6-mediated ubiquitination to suppress prostate cancer. Oncogene 36, 1364-1373. doi: 10.1038/onc.2016.300

Lu, Y. Y., Li, Z. Z., Jiang, D. S., Wang, L., Zhang, Y., Chen, K., et al. (2013). TRAF1 is a critical regulator of cerebral ischaemia-reperfusion injury and neuronal death. Nat. Commun. 4:2852. doi: 10.1038/ncomms3852

Lv, H., Dong, W., Guo, K., Jin, M., Li, X., Li, C., et al. (2018). Tumor necrosis factor receptor-associated factor 5 interacts with the NS3 protein and promotes classical swine fever virus replication. Viruses 10:305. doi: 10.3390/v100 60305

Lv, Y., Kim, K., Sheng, Y., Cho, J., Qian, Z., Zhao, Y. Y., et al. (2018). YAP Controls Endothelial Activation and Vascular Inflammation Through TRAF6. Circ. Res. 123, 43-56. doi: 10.1161/circresaha.118.313143

Mambetsariev, N., Lin, W. W., Stunz, L. L., Hanson, B. M., Hildebrand, J. M., and Bishop, G. A. (2016). Nuclear TRAF3 is a negative regulator of CREB in B cells. Proc. Natl. Acad. Sci. U.S.A. 113, 1032-1037. doi: 10.1073/pnas.1514 586113

Matsuzawa, A., Tseng, P. H., Vallabhapurapu, S., Luo, J. L., Zhang, W., Wang, H., et al. (2008). Essential cytoplasmic translocation of a cytokine receptorassembled signaling complex. Science 321, 663-668. doi: 10.1126/science. 1157340

Min, Y., Kim, M. J., Lee, S., Chun, E., and Lee, K. Y. (2018). Inhibition of TRAF6 ubiquitin-ligase activity by PRDX1 leads to inhibition of NFKB activation and autophagy activation. Autophagy 14, 1347-1358. doi: 10.1080/15548627.2018. 1474995

Missiou, A., Rudolf, P., Stachon, P., Wolf, D., Varo, N., Aichele, P., et al. (2010). TRAF5 deficiency accelerates atherogenesis in mice by increasing inflammatory cell recruitment and foam cell formation. Circ. Res. 107, 757-766. doi: 10.1161/ circresaha.110.219295

Monga, S. P. (2018). Lipid metabolic reprogramming in hepatic ischemiareperfusion injury. Nat. Med. 24, 6-7. doi: 10.1038/nm.4468

Nagashima, H., Ishii, N., and So, T. (2018). Regulation of interleukin-6 receptor signaling by TNF receptor-associated factor 2 and 5 during differentiation of inflammatory CD4(+) T Cells. Front. Immunol. 9:1986. doi: 10.3389/fimmu. 2018.01986

Nakamura, K., Kageyama, S., Kaldas, F. M., Hirao, H., Ito, T., Kadono, K., et al. (2020). Hepatic CEACAM1 expression indicates donor liver quality and prevents early transplantation injury. J. Clin. Invest. 130, 2689-2704. doi: 10. $1172 /$ jci133142

Ni, D., Wei, H., Chen, W., Bao, Q., Rosenkrans, Z. T., Barnhart, T. E., et al. (2019). Ceria nanoparticles meet hepatic ischemia-reperfusion injury: the perfect imperfection. Adv. Mater. 31:e1902956. doi: 10.1002/adma.201902956 
Noguchi, T., Takeda, K., Matsuzawa, A., Saegusa, K., Nakano, H., Gohda, J., et al. (2005). Recruitment of tumor necrosis factor receptor-associated factor family proteins to apoptosis signal-regulating kinase 1 signalosome is essential for oxidative stress-induced cell death. J. Biol. Chem. 280, 37033-37040. doi: 10. 1074/jbc.M506771200

Park, H. H. (2018). Structure of TRAF family: current understanding of receptor recognition. Front. Immunol. 9:1999. doi: 10.3389/fimmu.2018. 01999

Perez-Chacon, G., Adrados, M., Vallejo-Cremades, M. T., Lefebvre, S., Reed, J. C., and Zapata, J. M. (2018). Dysregulated TRAF3 and BCL2 expression promotes multiple classes of mature non-hodgkin B cell lymphoma in mice. Front. Immunol. 9:3114. doi: 10.3389/fimmu.2018.03114

Qi, Y., Zhao, M., Bai, Y., Huang, L., Yu, W., Bian, Z., et al. (2014). Retinal ischemia/reperfusion injury is mediated by Toll-like receptor 4 activation of NLRP3 inflammasomes. Invest. Ophthalmol. Vis. Sci. 55, 5466-5475. doi: 10. 1167/iovs.14-14380

Qin, J. J., Mao, W., Wang, X., Sun, P., Cheng, D., Tian, S., et al. (2018). Caspase recruitment domain 6 protects against hepatic ischemia/reperfusion injury by suppressing ASK1. J. Hepatol. 69, 1110-1122. doi: 10.1016/j.jhep.2018.06.014

Qin, X., Li, N., Zhang, M., Lin, S., Zhu, J., Xiao, D., et al. (2019). Tetrahedral framework nucleic acids prevent retina ischemia-reperfusion injury from oxidative stress via activating the Akt/Nrf2 pathway. Nanoscale 11, 2066720675. doi: 10.1039/c9nr07171g

Qiu, Z., Lei, S., Zhao, B., Wu, Y., Su, W., Liu, M., et al. (2017). NLRP3 inflammasome activation-mediated pyroptosis aggravates myocardial ischemia/reperfusion injury in diabetic rats. Oxid. Med. Cell. Longev. 2017:9743280. doi: 10.1155/2017/9743280

Qu, F., Xiang, Z., Zhou, Y., and Qin, Y. (2017). A molluscan TNF receptorassociated factor 2 (TRAF2) was involved in host defense against immune challenges. Fish Shellfish Immunol. 71, 105-115. doi: 10.1016/j.fsi.2017.09.076

Ren, H. Y., Wang, J., Yang, F., Zhang, X. L., Wang, A. L., Sun, L. L., et al. (2015). Cytoplasmic TRAF4 contributes to the activation of p70s6k signaling pathway in breast cancer. Oncotarget 6, 4080-4096. doi: 10.18632/ oncotarget.2977

Reuss, D. E., Piro, R. M., Jones, D. T., Simon, M., Ketter, R., Kool, M., et al. (2013). Secretory meningiomas are defined by combined KLF4 K409Q and TRAF7 mutations. Acta Neuropathol. 125, 351-358. doi: 10.1007/s00401-013-1093-x

Robeson, A. C., Lindblom, K. R., Wojton, J., Kornbluth, S., and Matsuura, K. (2018). Dimer-specific immunoprecipitation of active caspase-2 identifies TRAF proteins as novel activators. EMBO J. 37:e97072. doi: 10.15252/embj. 201797072

Rousseau, A., Wilhelm, L. P., Tomasetto, C., and Alpy, F. (2014). The phosphoinositide-binding protein TRAF4 modulates tight junction stability and migration of cancer cells. Tissue Barriers 2:e975597. doi: 10.4161/21688370. 2014.975597

Russo, R., Varano, G. P., Adornetto, A., Nazio, F., Tettamanti, G., Girardello, R., et al. (2018). Rapamycin and fasting sustain autophagy response activated by ischemia/reperfusion injury and promote retinal ganglion cell survival. Cell Death Dis. 9:981. doi: 10.1038/s41419-018-1044-5

Sajjad, N., Mir, M. M., Khan, J., Rather, I. A., and Bhat, E. A. (2019). Recognition of TRAIP with TRAFs: current understanding and associated diseases. Int. J. Biochem. Cell Biol. 115:105589. doi: 10.1016/j.biocel.2019. 105589

Sakauchi, C., Wakatsuki, H., Ichijo, H., and Hattori, K. (2017). Pleiotropic properties of ASK1. Biochim. Biophys. Acta Gen. Subj. 1861(1 Pt A), 3030-3038. doi: 10.1016/j.bbagen.2016.09.028

Sangare, L. O., Yang, N., Konstantinou, E. K., Lu, D., Mukhopadhyay, D., Young, L. H., et al. (2019). Toxoplasma GRA15 activates the NF-kappaB pathway through interactions with TNF receptor-associated factors. mBio 10:e00808-19. doi: 10.1128/mBio.00808-19

Schneider, A. T., Gautheron, J., Feoktistova, M., Roderburg, C., Loosen, S. H., Roy, S., et al. (2017). RIPK1 suppresses a TRAF2-dependent pathway to liver cancer. Cancer Cell 31, 94-109. doi: 10.1016/j.ccell.2016.11.009

Shang, J., Li, L., Wang, X., Pan, H., Liu, S., He, R., et al. (2016). Disruption of tumor necrosis factor receptor-associated factor 5 exacerbates murine experimental colitis via regulating $\mathrm{T}$ helper cell-mediated inflammation. Mediat. Inflamm. 2016:9453745. doi: 10.1155/2016/9453745
Shao, Z., Jiao, B., Liu, T., Cheng, Y., Liu, H., and Liu, Y. (2016). TAK242 treatment ameliorates liver ischemia/reperfusion injury by inhibiting TLR4 signaling pathway in a swine model of Maastricht-category-III cardiac death. Biomed. Pharmacother. 84, 495-501. doi: 10.1016/j.biopha.2016. 09.036

Shen, C. H., Lin, J. Y., Chang, Y. L., Wu, S. Y., Peng, C. K., Wu, C. P., et al. (2018). Inhibition of NKCC1 modulates alveolar fluid clearance and inflammation in ischemia-reperfusion lung injury via TRAF6mediated pathways. Front. Immunol. 9:2049. doi: 10.3389/fimmu.2018. 02049

Shen, J., Qiao, Y., Ran, Z., and Wang, T. (2013). Different activation of TRAF4 and TRAF6 in inflammatory bowel disease. Mediat. Inflamm. 2013:647936. doi: $10.1155 / 2013 / 647936$

Shirakura, K., Ishiba, R., Kashio, T., Funatsu, R., Tanaka, T., Fukada, S. I., et al. (2019). The Robo4-TRAF7 complex suppresses endothelial hyperpermeability in inflammation. J. Cell Sci. 132:jcs220228. doi: 10.1242/jcs.220228

Siu, K. L., Yuen, K. S., Castaño-Rodriguez, C., Ye, Z. W., Yeung, M. L., Fung, S. Y., et al. (2019). Severe acute respiratory syndrome coronavirus ORF3a protein activates the NLRP3 inflammasome by promoting TRAF3dependent ubiquitination of ASC. FASEB J. 33, 8865-8877. doi: 10.1096/fj.2018 02418R

Stevers, M., Rabban, J. T., Garg, K., Van Ziffle, J., Onodera, C., Grenert, J. P., et al. (2019). Well-differentiated papillary mesothelioma of the peritoneum is genetically defined by mutually exclusive mutations in TRAF7 and CDC42. Mod. Pathol. 32, 88-99. doi: 10.1038/s41379-018-0127-2

Su, D., Cheng, Y., Li, S., Dai, D., Zhang, W., and Lv, M. (2017). Sphk1 mediates neuroinflammation and neuronal injury via TRAF2/NF- $\kappa$ B pathways in activated microglia in cerebral ischemia reperfusion. J. Neuroimmunol. 305, 35-41. doi: 10.1016/j.jneuroim.2017.01.015

Sukhotnik, I., Ben Shahar, Y., Halabi, S., Bitterman, N., Dorfman, T., Pollak, Y., et al. (2019). Effect of N-acetylserotonin on TLR-4 and MyD88 expression during intestinal ischemia-reperfusion in a rat model. Eur. J. Pediatr. Surg. 29, 188-195. doi: 10.1055/s-0037-1618593

Swaidani, S., Liu, C., Zhao, J., Bulek, K., and Li, X. (2019). TRAF regulation of IL-17 cytokine signaling. Front. Immunol. 10:1293. doi: 10.3389/fimmu.2019.01293

Tajima, T., Yoshifuji, A., Matsui, A., Itoh, T., Uchiyama, K., Kanda, T., et al. (2019). $\beta$-hydroxybutyrate attenuates renal ischemia-reperfusion injury through its anti-pyroptotic effects. Kidney Int. 95, 1120-1137. doi: 10.1016/j.kint.2018.11. 034

Tan, Z., Shi, Y., Yan, Y., Liu, W., Li, G., and Li, R. (2015). Impact of endogenous hydrogen sulfide on toll-like receptor pathway in renal ischemia/reperfusion injury in rats. Ren. Fail. 37, 727-733. doi: 10.3109/0886022x.2015.10 12983

Tao, X., Sun, X., Yin, L., Han, X., Xu, L., Qi, Y., et al. (2015). Dioscin ameliorates cerebral ischemia/reperfusion injury through the downregulation of TLR4 signaling via HMGB-1 inhibition. Free Radic. Biol. Med. 84, 103-115. doi: 10.1016/j.freeradbiomed.2015.03.003

Tokita, M. J., Chen, C. A., Chitayat, D., Macnamara, E., Rosenfeld, J. A., Hanchard, N., et al. (2018). De novo missense variants in TRAF7 cause developmental delay, congenital anomalies, and dysmorphic features. Am. J. Hum. Genet. 103, 154-162. doi: 10.1016/j.ajhg.2018.06.005

Tonnus, W., and Linkermann, A. (2016). "Death is my heir"-ferroptosis connects cancer pharmacogenomics and ischemia-reperfusion injury. Cell. Chem. Biol. 23, 202-203. doi: 10.1016/j.chembiol.2016.02.005

Trompouki, E., Hatzivassiliou, E., Tsichritzis, T., Farmer, H., Ashworth, A., and Mosialos, G. (2003). CYLD is a deubiquitinating enzyme that negatively regulates NF-kappaB activation by TNFR family members. Nature 424, $793-$ 796. doi: 10.1038/nature 01803

Tzeng, H. P., Evans, S., Gao, F., Chambers, K., Topkara, V. K., Sivasubramanian, N., et al. (2014). Dysferlin mediates the cytoprotective effects of TRAF2 following myocardial ischemia reperfusion injury. J. Am. Heart Assoc. 3:e000662. doi: $10.1161 /$ jaha.113.000662

Wallis, A. M., and Bishop, G. A. (2018). TRAF3 regulation of inhibitory signaling pathways in $\mathrm{B}$ and $\mathrm{T}$ lymphocytes by kinase and phosphatase localization. J. Leukoc. Biol. [Epub ahead of print]. doi: 10.1002/jlb.2mir0817-339rr

Wang, L., Lu, Y., Guan, H., Jiang, D., Guan, Y., Zhang, X., et al. (2013). Tumor necrosis factor receptor-associated factor 5 is an essential mediator 
of ischemic brain infarction. J. Neurochem. 126, 400-414. doi: 10.1111/jnc. 12207

Wang, Q., Gao, G., Zhang, T., Yao, K., Chen, H., Park, M. H., et al. (2018). TRAF1 is critical for regulating the BRAF/MEK/ERK pathway in non-small cell lung carcinogenesis. Cancer Res. 78, 3982-3994. doi: 10.1158/0008-5472.can-180429

Wang, X., Ha, T., Liu, L., Zou, J., Zhang, X., Kalbfleisch, J., et al. (2013). Increased expression of microRNA-146a decreases myocardial ischaemia/reperfusion injury. Cardiovasc. Res. 97, 432-442. doi: 10.1093/cvr/cvs356

Wang, X., Ha, T., Zou, J., Ren, D., Liu, L., Zhang, X., et al. (2014). MicroRNA$125 \mathrm{~b}$ protects against myocardial ischaemia/reperfusion injury via targeting p53-mediated apoptotic signalling and TRAF6. Cardiovasc. Res. 102, 385-395. doi: $10.1093 / \mathrm{cvr} / \mathrm{cvu} 044$

Wang, X., Yang, J., Han, L., Zhao, K., Wu, Q., Bao, L., et al. (2015). TRAF5mediated Lys-63-linked polyubiquitination plays an essential role in positive regulation of ROR $\gamma \mathrm{t}$ in promoting IL-17A expression. J. Biol. Chem. 290, 29086-29094. doi: 10.1074/jbc.M115.664573

Wang, Y., Chen, G., Yu, X., Li, Y., Zhang, L., He, Z., et al. (2016). Salvianolic acid $\mathrm{B}$ ameliorates cerebral ischemia/reperfusion injury through inhibiting TLR4/MyD88 signaling pathway. Inflammation 39, 1503-1513. doi: 10.1007/ s10753-016-0384-5

Wang, Z. H., Liu, J. L., Wu, L., Yu, Z., and Yang, H. T. (2014). Concentrationdependent wrestling between detrimental and protective effects of $\mathrm{H} 2 \mathrm{O} 2$ during myocardial ischemia/reperfusion. Cell Death Dis. 5:e1297. doi: 10.1038/cddis. 2014.267

Wei, B., Ruan, J., Mi, Y., Hu, J., Zhang, J., Wang, Z., et al. (2017). Knockdown of TNF receptor-associated factor 2 (TRAF2) modulates in vitro growth of TRAIL-treated prostate cancer cells. Biomed. Pharmacother. 93, 462-469. doi: 10.1016/j.biopha.2017.05.145

Whillock, A. L., Mambetsariev, N., Lin, W. W., Stunz, L. L., and Bishop, G. A. (2019). TRAF3 regulates the oncogenic proteins Pim 2 and c-Myc to restrain survival in normal and malignant B cells. Sci. Rep. 9:12884. doi: 10.1038/s41598019-49390-9

Xia, H., Li, Y., Wang, Z., Chen, W., Cheng, J., Yu, D., et al. (2019). Expression and functional analysis of tumor necrosis factor receptor (TNFR)-associated factor 5 from Nile tilapia, Oreochromis niloticus. Fish Shellfish Immunol. 93, 781-788. doi: 10.1016/j.fsi.2019.07.052

Xia, Y., Rao, J., Yao, A., Zhang, F., Li, G., Wang, X., et al. (2012). Lithium exacerbates hepatic ischemia/reperfusion injury by inhibiting GSK-3 $\beta / N F-\kappa B-$ mediated protective signaling in mice. Eur. J. Pharmacol. 697, 117-125. doi: 10.1016/j.ejphar.2012.09.009

Xiao, D., Liu, D., Wen, Z., Huang, X., Zeng, C., Zhou, Z., et al. (2019). Interaction between susceptibility loci in MAVS and TRAF3 genes, and high-risk HPV infection on the risk of cervical precancerous lesions in chinese population. Cancer Prev. Res. 12, 57-66. doi: 10.1158/1940-6207.capr-1 8-0177

Xie, M., Yin, Y., Chen, L., Yin, A., Liu, Y., Liu, Y., et al. (2020). Scavenger receptor A impairs interferon response to HBV infection by limiting TRAF3 ubiquitination through recruiting OTUB1. FEBS J. 287, 310-324. doi: 10.1111/febs.15035

Xie, P. (2013). TRAF molecules in cell signaling and in human diseases. J. Mol. Signal. 8:7. doi: 10.1186/1750-2187-8-7

Xu, L., Zhang, Y., Qu, X., Che, X., Guo, T., Li, C., et al. (2017). DR5-Cbl-b/cCbl-TRAF2 complex inhibits TRAIL-induced apoptosis by promoting TRAF2mediated polyubiquitination of caspase- 8 in gastric cancer cells. Mol. Oncol. 11, 1733-1751. doi: 10.1002/1878-0261.12140

Xu, T., Ding, W., Ao, X., Chu, X., Wan, Q., Wang, Y., et al. (2019). ARC regulates programmed necrosis and myocardial ischemia/reperfusion injury through the inhibition of mPTP opening. Redox Biol. 20, 414-426. doi: 10.1016/j.redox. 2018.10.023

Xu, W., Zhang, L., Ma, S., Zhang, Y., Cai, Z., Zhang, K., et al. (2020). TRAF5 protects against myocardial ischemia reperfusion injury via AKT signaling. Eur. J. Pharmacol. 878:173092. doi: 10.1016/j.ejphar.2020.173092

Xu, W., Zhang, L., Zhang, Y., Zhang, K., Wu, Y., and Jin, D. (2019). TRAF1 exacerbates myocardial ischemia reperfusion injury via ASK1-JNK/p38 signaling. J. Am. Heart Assoc. 8:e012575. doi: 10.1161/jaha.119.012575

Xu, X., Wang, M., Li, J. Z., Wei, S. D., Wu, H., Lai, X., et al. (2018). Tauroursodeoxycholic acid alleviates hepatic ischemia reperfusion injury by suppressing the function of Kupffer cells in mice. Biomed. Pharmacother. 106, 1271-1281. doi: 10.1016/j.biopha.2018.06.046

Yang, F., Wang, J., Ren, H. Y., Jin, J., Wang, A. L., Sun, L. L., et al. (2015). Proliferative role of TRAF4 in breast cancer by upregulating PRMT5 nuclear expression. Tumour Biol. 36, 5901-5911. doi: 10.1007/s13277-015-3262-0

Yi, P., Xia, W., Wu, R. C., Lonard, D. M., Hung, M. C., and O’Malley, B. W. (2013). SRC-3 coactivator regulates cell resistance to cytotoxic stress via TRAF4mediated p53 destabilization. Genes Dev. 27, 274-287. doi: 10.1101/gad.203760. 112

Yi, Z., Deng, M., Scott, M. J., Fu, G., Loughran, P. A., Lei, Z., et al. (2020). IRG1/Itaconate Activates Nrf2 in hepatocytes to protect against liver ischemiareperfusion injury. Hepatology [Epub ahead of print]. doi: 10.1002/hep. 31147

Yu, S. Y., Dong, B., Fang, Z. F., Hu, X. Q., Tang, L., and Zhou, S. H. (2018). Knockdown of lncRNA AK139328 alleviates myocardial ischaemia/reperfusion injury in diabetic mice via modulating miR-204-3p and inhibiting autophagy. J. Cell. Mol. Med. 22, 4886-4898. doi: 10.1111/jcmm. 13754

Zapata, J. M., Perez-Chacon, G., Carr-Baena, P., Martinez-Forero, I., Azpilikueta, A., Otano, I., et al. (2018). CD137 (4-1BB) signalosome: complexity is a matter of TRAFs. Front. Immunol. 9:2618. doi: 10.3389/fimmu.2018.02618

Zhang, J., Chen, T., Yang, X., Cheng, H., Späth, S. S., Clavijo, P. E., et al. (2018). Attenuated TRAF3 fosters activation of alternative NF- $\kappa$ B and reduced expression of antiviral interferon, TP53, and RB to promote HPV-positive head and neck cancers. Cancer Res. 78, 4613-4626. doi: 10.1158/0008-5472.can-170642

Zhang, J., Fu, B., Zhang, X., Chen, L., Zhang, L., Zhao, X., et al. (2013). Neuroprotective effect of bicyclol in rat ischemic stroke: down-regulates TLR4, TLR9, TRAF6, NF-кB, MMP-9 and up-regulates claudin-5 expression. Brain Res. 1528, 80-88. doi: 10.1016/j.brainres.2013.06.032

Zhang, M. H., Zhang, H. H., Du, X. H., Gao, J., Li, C., Shi, H. R., et al. (2020). UCHL3 promotes ovarian cancer progression by stabilizing TRAF2 to activate the NF-kappaB pathway. Oncogene 39, 322-333. doi: 10.1038/s41388-0190987-z

Zhang, R., Xu, L., Zhang, D., Hu, B., Luo, Q., Han, D., et al. (2018). Cardioprotection of ginkgolide B on myocardial ischemia/reperfusion-induced inflammatory injury via regulation of A20-NF-кB pathway. Front. Immunol. 9:2844. doi: 10.3389/fimmu.2018.02844

Zhang, T., Xiu, H. H., Liu, J. X., Ma, Y., Xu, K. Q., and Huang, W. Q. (2017). Protective effect of aspirin-triggered resolvin D1 on hepatic ischemia/reperfusion injury in rats: the role of miR-146b. Int. Immunopharmacol. 51, 140-147. doi: 10.1016/j.intimp.2017.08.008

Zhang, X., Lin, C., Song, J., Chen, H., Chen, X., Ren, L., et al. (2019). Parkin facilitates proteasome inhibitor-induced apoptosis via suppression of NF-кB activity in hepatocellular carcinoma. Cell Death Dis. 10:719. doi: 10.1038/ s41419-019-1881-x

Zhang, X. F., Zhang, R., Huang, L., Wang, P. X., Zhang, Y., Jiang, D. S., et al. (2014). TRAF1 is a key mediator for hepatic ischemia/reperfusion injury. Cell Death Dis. 5:e1467. doi: 10.1038/cddis.2014.411

Zhang, Z., Zhang, T., Feng, R., Huang, H., Xia, T., and Sun, C. (2019). circARF3 alleviates mitophagy-mediated inflammation by targeting miR-103/TRAF3 in mouse adipose tissue. Mol. Ther. Nucleic Acids 14, 192-203. doi: 10.1016/j. omtn.2018.11.014

Zhou, H., Li, D., Zhu, P., Ma, Q., Toan, S., Wang, J., et al. (2018). Inhibitory effect of melatonin on necroptosis via repressing the Ripk3-PGAM5-CypD-mPTP pathway attenuates cardiac microvascular ischemia-reperfusion injury. J. Pineal Res. 65:e12503. doi: 10.1111/jpi.12503

Zhou, H., Zhu, P., Guo, J., Hu, N., Wang, S., Li, D., et al. (2017). Ripk3 induces mitochondrial apoptosis via inhibition of FUNDC1 mitophagy in cardiac IR injury. Redox. Biol. 13, 498-507. doi: 10.1016/j.redox.2017.07.007

Zhou, W., Yao, J., Wang, G., Chen, Z., Li, Z., Feng, D., et al. (2017). PKCzeta phosphorylates TRAF2 to protect against intestinal ischemia-reperfusioninduced injury. Cell Death Dis. 8:e2935. doi: 10.1038/cddis.2017.310

Zhou, X., Liu, Z., Cheng, X., Zheng, Y., Zeng, F., and He, Y. (2015). Socs1 and Socs3 degrades Traf6 via polyubiquitination in LPS-induced acute necrotizing pancreatitis. Cell Death Dis. 6:e2012. doi: 10.1038/cddis.20 15.342 
Zhu, L., Xu, C., Huo, X., Hao, H., Wan, Q., Chen, H., et al. (2019). The cyclooxygenase-1/mPGES-1/endothelial prostaglandin EP4 receptor pathway constrains myocardial ischemia-reperfusion injury. Nat. Commun. 10:1888. doi: 10.1038/s41467-019-09492-4

Zhu, S., Jin, J., Gokhale, S., Lu, A. M., Shan, H., Feng, J., et al. (2018). Genetic alterations of TRAF proteins in human cancers. Front. Immunol. 9:2111. doi: 10.3389/fimmu.2018.02111

Zotti, T., Scudiero, I., Vito, P., and Stilo, R. (2017). The emerging role of TRAF7 in tumor development. J. Cell. Physiol. 232, 1233-1238. doi: 10.1002/jcp. 25676
Conflict of Interest: The authors declare that the research was conducted in the absence of any commercial or financial relationships that could be construed as a potential conflict of interest.

Copyright $\odot 2020$ Zhou, Lin, Zhong and Ye. This is an open-access article distributed under the terms of the Creative Commons Attribution License (CC BY). The use, distribution or reproduction in other forums is permitted, provided the original author(s) and the copyright owner(s) are credited and that the original publication in this journal is cited, in accordance with accepted academic practice. No use, distribution or reproduction is permitted which does not comply with these terms. 